\title{
Synchrotron 4D X-Ray Imaging Reveals Strain Localization at the Onset of System-Size Failure in Porous Reservoir Rocks
}

\author{
Neelima Kandula, ${ }^{1,2}$ Jessica McBeck, ${ }^{1,2}$ Benoît Cordonnier, ${ }^{1,2,3}$ Jérôme Weiss, ${ }^{4}$ Dag Kristian Dysthe, ${ }^{1,2}$ and \\ FrançOIS RENARD ${ }^{1,2,4}$ (i)
}

\begin{abstract}
Understanding the mechanisms of strain localization leading to brittle failure in reservoir rocks can shed light on geomechanical processes such as porosity and permeability evolution during rock deformation, induced seismicity, fracturing, and subsidence in geological reservoirs. We perform triaxial compression tests on three types of porous reservoir rocks to reveal the local deformation mechanisms that control system-size failure. We deformed cylindrical samples of Adamswiller sandstone (23\% porosity), Bentheim sandstone (23\% porosity), and Anstrude limestone (20\% porosity), using an X-ray transparent triaxial deformation apparatus. This apparatus enables the acquisition of three-dimensional synchrotron X-ray images, under in situ stress conditions. Analysis of the tomograms provide 3D distributions of the microfractures and dilatant pores from which we calculated the evolving macroporosity. Digital volume correlation analysis reveals the dominant strain localization mechanisms by providing the incremental strain components of pairs of tomograms. In the three rock types, damage localized as a single shear band or by the formation of conjugate bands at failure. The porosity evolution closely matches the evolution of the incremental strain components of dilation, contraction, and shear. With increasing confinement, the dominant strain in the sandstones shifts from dilative strain (Bentheim sandstone) to contractive strain (Adamswiller sandstone). Our study also links the formation of compactive shear bands with porosity variations in Anstrude limestone, which is characterized by a complex pore geometry. Scanning electron microscopy images indicate that the microscale mechanisms guiding strain localization are pore collapse and grain crushing in sandstones, and pore collapse, pore-emanated fractures and cataclasis in limestones. Our dynamic X-ray microtomography data brings unique insights on the correlation between the evolutions of rock microstructure, porosity evolution, and macroscopic strain during the approach to brittle failure in reservoir rocks.
\end{abstract}

Supplementary Information The online version contains supplementary material available at https://doi.org/10.1007/s00024021-02902-z.

1 The Njord Centre, Department of Geosciences, University of Oslo, Oslo, Norway. E-mail: francois.renard@geo.uio.no

2 The Njord Centre, Department of Physics, University of Oslo, Oslo, Norway.

3 The European Synchrotron, ESRF, Beamline ID19, Grenoble, France.

4 Université Grenoble Alpes, Université Savoie Mont Blanc, CNRS, IFSTTAR, 38000 Grenoble, IRDISTerre, France.
Keywords: X-ray tomography, porous rocks, brittle failure.

\section{Introduction}

Strain localization in rocks and geomaterials (e.g., cement) is observed over a broad range of length scales, varying from centimeter-sized laboratory rock specimens (e.g., Lockner et al., 1991; Paterson \& Wong, 2005; Renard et al., 2019a) to crustal fault zones stretching over several kilometers (e.g., Cilona et al., 2012; Fossen et al., 2007, 2018; Rotevatn et al., 2016). Strain localization within reservoir rocks can occur as deformation bands (e.g. Aydin \& Johnson, 1978; Shipton \& Cowie, 2001). These features influence permeability and thus fluid flow in sedimentary basins (e.g. Bjørlykke, 1993), and reservoir compaction and subsidence (e.g. Nagel, 2001). In sandstone and carbonate reservoirs, open and subsequently cemented fracture networks and deformation bands are the main structural features.

Recent studies (Baud et al., 2017b; Huang et al., 2019; Ji et al., 2015; Louis et al., 2007; Renard et al., 2019a; Wong \& Baud, 2012) have argued for a systematic microstructural characterization including $\mathrm{X}$-ray computed tomography $(\mu \mathrm{CT})$ and digital volume correlation technique to provide a consistent description of the multiscale mechanics of strain localization in porous reservoir rocks. With this motivation, we present here triaxial deformation tests on Adamswiller sandstone, Bentheim sandstone and Anstrude limestone (of comparable porosities 20-23\%) subjected to low and intermediate confining pressures (5-30 MPa). We employ synchrotron X-ray microcomputed tomography imaging and scanning 
electron microscopy imaging (SEM) for microstructural characterization. We also perform digital volume correlation to compute the incremental strain accumulated toward system-size failure. Recent experiments have elucidated strain localization mechanisms in a sandstone (Renard et al., 2019a) and a limestone (Huang et al., 2019) using the same experimental technique. Our experimental technique quantifies the combination of aseismic and seismic deformation components, which cannot be estimated through other experimental techniques. Computing the local strain tensors provides close constraints on the dominant deformation mechanism that defines the failure mode. Recent studies using digital volume correlation (McBeck et al., 2019b, 2020; Renard et al., 2019a, 2019b; Zheng et al., 2019) have shown that the distribution and localization of damage in a range of rock types are mixed-mode, involving contributions from both tensile, compressive, and shear components of strain. The effectiveness of the digital volume correlation technique enables the present study to address the microscale and macroscale characterization of the failure modes and strain localization mechanisms between two classes of reservoir rocks with similar initial porosity (sandstones and limestones with $20-23 \%$ porosity). We also show an interplay between dilatancy, compaction and shear that affects the variations in porosity during deformation both at the scale of the entire sample, and also at the local scale of subvolumes in the sample. Finally, we discuss how the strain localization mechanisms in sandstones and limestones are defined by the underlying microstructure and pore geometry in these respective rock types. In sandstones, brittle deformation is dominated by either dilative or contractive strain subjected to applied confinement. Conversely, in five Anstrude limestone samples strain components do not show any particular trend with variation in applied confinement, which can be attributed to the complex microstructure and presence of a micro- and macroporosity. Therefore, in Anstrude \#2, \#3, \#4 and \#6, strain localization is mixed-mode, which means at any given instance of the experiment, strain has contributions from dilation, contraction and shear. On one hand, microscale mechanisms guiding strain localization in sandstones are pore space dilation or pore collapse along with grain crushing. On the other hand, pore collapse, grain crushing with cataclasis and pore-emanating fractures constitute the microscale processes in limestones. Applied confinement also plays a major role in determining microscale mechanisms and strain localization in porous rocks.

\section{Background}

\subsection{Deformation Bands in Sandstone and Limestone}

Deformation bands in sandstones may form by a combination of shear and compaction. A kinematic classification system of deformation bands depends on the competition between these two end-members. Bands of localization where shear displacement exceeds compaction are categorized as compaction shear bands (Fossen et al., 2018; Zuluaga et al., 2014). Bands where compaction and shear are of comparable magnitude are described as shear-enhanced compaction bands (e.g., Ballas et al., 2013) and those dominated by compaction are pure compaction bands (e.g., Fossen et al., 2011). Shearenhanced compaction bands are characterized by high dihedral angles ( $47^{\circ}$ in Entrada Sandstone, Utah, Fossen et al., 2018; where the dihedral angle is the angle measured between the conjugate deformation bands) and pure compaction bands are formed perpendicular to maximum principle stress (Fossen et al., 2011). Dilatational bands with a higher porosity than the host rock have been observed in Nubian Sandstone in Sinai (Fossen et al., 2007). Dilatational bands may increase the permeability while the compaction bands decrease it (Zuluaga et al., 2014).

Due to complexity in the pore space, grain assemblage and mineralogy, carbonate rocks are in many aspects different from sandstones. Similar to sandstones, strain localization in carbonate rocks is sensitive to the pore geometry and grain size distribution (Cilona et al., 2014; Rustichelli et al., 2012), and can reduce the porosity and permeability (Rath et al., 2011; Tondi et al., 2016). Four main strain localization types have been identified in carbonate rocks within contractional and extensional tectonic settings: pure compaction bands (Rotevatn et al., 2016), narrow bands of compaction and shear 
described as compactional shear bands (e.g., Aydin, 1978; Rath et al., 2011), pressure solution at the grain contacts (Croizé et al., 2013) leading to the formation of solution-dominated compactional shear bands (Rutter, 1983), and cataclasis within the compactional shear bands forms cataclasis-dominant compactional shear bands (Rotevatn et al., 2016). In these four mechanisms, the deformation bands are formed by a combination of compaction, dilation, and shear strains that act at the grain scale and lead to the emergence of strain localization at the macroscopic scale. However, the individual contributions of these strain components remain to be characterized. Here, we perform experiments that allow correlating the local microscopic strain to macroscopic deformation that leads to shear failure in porous rocks.

\subsection{Laboratory Experiments of Sandstone and Limestone Brittle Deformation}

Many studies have analyzed inelastic deformation and strain localization in sandstones and limestones with varying porosities and under a range of confining pressures in the laboratory (e.g. Baud et al., 2000, 2017a, 2017b; Brantut et al., 2014; Fortin et al., 2009; Ji et al., 2015; Olsson \& Holcomb, 2000; Scott \& Nielsen, 1991; Vajdova et al., 2010; Wong \& Baud, 2012; Wong et al., 1997). Brittle faulting in a porous rock under compressive loading is generally accompanied by shear localization. However, field and laboratory studies have documented that the failure mode in porous rocks is highly dependent on the confinement, and rock type. With increasing confining pressure, the failure mode in both sandstones (Menéndez et al., 1996; Zhu \& Wong, 1997) and limestones (Baud et al., 2017c; Vajdova et al., 2010) shows a transition from brittle faulting to cataclastic flow and then ductile deformation, which is an universal behavior in compressive failure (Renshaw \& Schulson, 2001). Under low confinement (5 MPa), dilatancy leads to shear localization at macroscopic failure whereas at higher confinement, cataclasis results in shear-enhanced compaction and strain hardening. The confinement pressure under which this transition occurs depends on rock type. Thin sections of failed limestone samples deformed under intermediate confinement did not show evidence of high-angle shear bands or diffusive compaction bands, indicative of higher confinement (Baud et al., 2017a; Ji et al., 2015). However, triaxially compressed Leitha limestone formed discrete compaction bands at intermediate confinement (Huang et al., 2019). Therefore, the microstructural origin of strain localization in this transitional regime of 20-40 MPa confining pressure remains an open question.

Strain localization and porosity evolution are closely connected with the failure mode, and vary depending on the initial porosities and pore geometries of individual rocks. Triaxial tests on porous carbonate rocks (e.g., Baud et al., 2017a; Huang et al., 2019) have classified failure modes based on the initial porosity and applied confinement. The failure mode at low confinement in carbonate rock cores with high initial porosity is dominated by compaction and tend to form compaction bands. The failure mode in lower porosity carbonates includes a combination of compaction and shear resulting in compaction shear bands and conjugate shear bands.

Strain localization in rocks results from the properties of elastic interactions into a heterogeneous solid, which are anisotropic (Dansereau et al., 2019). In other words, microscale heterogeneities guide the nucleation and perseverance of damage (Brace, 1978). In the crust, these heterogeneities occur as pores, grains, grain boundaries, and the cement between the grains, and to larger heterogeneities such as fractures and bedding interfaces. Pore space can be comprised of numerous equant pores connected through narrow passages (pore throats). When an external stress field is applied, damage may nucleate on the grain scale heterogeneities and develop by the growth of microfractures and collapse of the pore space (McBeck et al., 2019a; Paterson \& Wong, 2005), perhaps through the redistribution of the stress field via force chains. When the rock is driven to larger stresses, fractures may coalesce to form localized zones of intense deformation. These localized zones extend over multiple grains and cut across the sample length (Brace, 1978).

Fracture nucleation and the characteristics of localized zones are sensitive to rock type, initial porosity, complexity of the pore geometry and loading conditions (Paterson \& Wong, 2005). 
Sandstones are comprised of angular grains with narrow grain size distributions and uniform pore space. Conversely, limestones may exhibit a more complex pore geometry because the pore size may span a broad range, and is often characterized by a bimodal distribution (Ji et al., 2015). Large pores between the grains may be surrounded by a myriad of small pores located inside the grains or in the cement. These two categories of pores may form two parallel networks, (1) macroporosity, which can be identified by optical microscopy and moderate resolution X-ray microtomography, (2) microporosity with submicron features not readily resolved by these standard techniques (Pittman, 1971), but may be identified by scanning electron microscopy or submicrometer X-ray microtomography (Ji et al., 2015). Previous analyses have identified and characterized the microscale mechanisms of grain crushing, pore collapse and pore-emanated fractures in the brittle failure mode under low confining pressures (Baud et al., 2017a; Vajdova et al., 2010; Wong \& Baud, 2012; Zhu \& Wong, 1997). Conversely, under higher confinement, larger amounts of cataclasis may lead to failure (Baud et al., 2017a; Ji et al., 2015). But an ambiguity exists about the microscale mechanisms associated with intermediate confining pressures (20$40 \mathrm{MPa})$.

Acoustic emission measurements provide an alternative technique for quantifying grain-scale damage localization related to faulting. Acoustic emission activity measured in Westerly granite (Lockner et al., 1992), a rock with $<1 \%$ porosity, revealed the spatiotemporal development of strain localization. For porous sandstones and limestones, acoustic emission data have revealed microfracturing events that were inferred to occur at grain interfaces (Baud et al., 2004, 2017b; Fortin et al., 2009; Olsson et al., 2002; Vajdova et al., 2004). These analyses have led to the conclusion that the spatial distribution of acoustic emission arises from (1) the formation of extensional fractures or (2) transgranular fractures due to grain breakage. From microstructural observations of the samples after the experiments, the dominant microscale mechanisms giving rise to compaction was identified as pore collapse (resulting from sliding between the grains), which does not generate significant amount of acoustic emission and therefore appeared aseismic in these experiments. This dominance of pore collapse was observed in diffusive compaction bands and high-angle shear bands in carbonate rocks ( $\mathrm{Ji}$ et al., 2015; Wong \& Baud, 2012), and compactional shear bands in sandstones (Louis et al., 2007; Vajdova et al., 2004). Complementary to acoustic emissions, our experiments using X-ray synchrotron can record deformation generated from both seismic and aseismic events and can better characterize the strain localization mechanisms responsible for strain localization in porous reservoir rocks.

\section{Methods}

\subsection{Triaxial Compression X-Ray Tomography Experiment}

We imaged in 4D under in situ stress conditions and ambient temperature the microstructural evolution of porous rocks subjected to triaxial compression until system-size (macroscopic) failure. Table 1 displays the various parameters used in the present study, and Table 2 shows the experimental conditions. We deformed samples using the X-ray transparent triaxial compression apparatus Hades (Renard et al., 2016), and acquired time series of images of the rock microstructure using time-lapse synchrotron X-ray microtomography. We performed seven experiments on porous reservoir rock samples, including one Adamswiller sandstone core (Rimmelé et al., 2010), one Bentheim sandstone core (Klein et al., 2001) and five Anstrude limestone cores (Lion et al., 2004; Renard et al., 2017). All the Anstrude samples were cored from the same block. These three rock types constitute a set of sandstones and limestones of comparable initial porosities (20$23 \%$ ) and are ideal for studying the relative variations in porosities, microstructural changes and strain localization mechanisms among them.

Adamswiller sandstone is a Triassic (Bundsandstein) sandstone from a quarry in Bas-Rhin. It is composed of $71 \%$ quartz, $9 \%$ feldspar, $11 \%$ clay, $5 \%$ mica, traces of apatite, and oxides of iron and titanium (Rimmelé et al., 2010). It has an average porosity of $23 \%$, mean grain size in the range $120 \mu \mathrm{m}$ 
Table 1

Symbols and parameters

\begin{tabular}{|c|c|}
\hline Parameters & Definition, units \\
\hline$\sigma_{1}$ & Axial stress, $\mathrm{MPa}$ \\
\hline$\sigma_{2}=\sigma_{3}$ & Confining stress (i.e. confining pressure), $\mathrm{MPa}$ \\
\hline$p_{0}$ & Pore fluid pressure, $\mathrm{MPa}$ \\
\hline$\sigma_{d}$ & Differential stress, $\sigma_{1}-\sigma_{3}$, with $\sigma_{2}=\sigma_{3}, \mathrm{MPa}$ \\
\hline$\sigma_{d}^{y}$ & Differential stress at yield, MPa \\
\hline$\sigma_{d}^{f}$ & Differential stress at the failure, $\mathrm{MPa}$ \\
\hline$\varepsilon_{z z}$ & Macroscopic axial strain, dimensionless \\
\hline$\varepsilon_{z z}^{f}$ & Macroscopic axial strain at failure, dimensionless \\
\hline$\varepsilon_{z z} / \varepsilon_{z z}^{f}$ & Normalized axial strain (in the range $\left[\begin{array}{ll}0 & 1\end{array}\right]$ ), dimensionless \\
\hline$\phi$ & $\begin{array}{l}\text { Porosity of the sample measured using segmented 3D tomograms, } \\
\text { dimensionless }\end{array}$ \\
\hline$\phi_{0}$ & $\begin{array}{l}\text { Initial porosity of the sample measured using segmented 3D } \\
\text { tomograms, dimensionless }\end{array}$ \\
\hline$\phi / \phi_{0}$ & Normalized porosity, dimensionless \\
\hline$\phi$ & Mean porosity in the sample, dimensionless \\
\hline$D_{\phi}=\frac{\phi-\phi_{0}}{1-\phi_{0}}$ & Porosity parameter, dimensionless \\
\hline$\overleftrightarrow{u}^{1-\varphi_{0}}$ & Incremental displacement field \\
\hline$\nabla \cdot \overleftrightarrow{\leftrightarrow}=\frac{\partial u_{x}}{\partial x}+\frac{\partial u_{y}}{\partial y}+\frac{\partial u_{z}}{\partial z}$ & Divergence of incremental displacement field \\
\hline$\nabla \cdot \overleftrightarrow{u}<0$ & Incremental contractive strain, dimensionless \\
\hline$\nabla \cdot \overleftrightarrow{u}>0$ & Incremental dilative strain, dimensionless \\
\hline$\nabla \times \overleftrightarrow{u}=\left|\frac{\partial u_{z}}{\partial v}-\frac{\partial u_{y}}{\partial z}\right| \hat{x}+\left|\frac{\partial u_{x}}{\partial z}-\frac{\partial u_{z}}{\partial x}\right| \hat{y}+\left|\frac{\partial u_{y}}{\partial x}-\frac{\partial u_{x}}{\partial v}\right| \hat{z}$ & Curl of incremental displacement field \\
\hline$\nabla \times \overleftrightarrow{u}<0$ & Left-lateral incremental shear strain, dimensionless \\
\hline$\nabla \times \overleftrightarrow{u}<0$ & Right-lateral incremental shear strain, dimensionless \\
\hline$I_{1}=\frac{\partial u_{x}}{\partial x}+\frac{\partial u_{y}}{\partial y}+\frac{\partial u_{z}}{\partial z}$ & First invariant of incremental strain, dimensionless \\
\hline$I_{2}=\left[\left(\frac{\partial u_{x}}{\partial x}\right)\left(\frac{\partial u_{y}}{\partial y}\right)+\left(\frac{\partial u_{y}}{\partial y}\right)\left(\frac{\partial u_{z}}{\partial z}\right)+\left(\frac{\partial u_{z}}{\partial z}\right)\left(\frac{\partial u_{x}}{\partial x}\right)-\left(\frac{\partial u_{x}}{\partial y}\right)^{2}-\left(\frac{\partial u_{y}}{\partial z}\right)^{2}-\left(\frac{\partial u_{z}}{\partial x}\right)^{2}\right]$ & Second invariant of incremental strain, dimensionless \\
\hline$J_{2}=1 / 3 I_{1}^{2}-I_{2}$ & Second invariant of strain deviatoric tensor, dimensionless \\
\hline$\sqrt{3 J_{2}}$ & Von Mises strain, dimensionless \\
\hline$\Delta \varepsilon_{z z}$ & $\begin{array}{l}\text { Difference of macroscopic axial strain between two tomograms used } \\
\text { for each digital volume calculation, dimensionless }\end{array}$ \\
\hline $\mid$ mean $/ \Delta \varepsilon_{z z} \mid$ & $\begin{array}{l}\text { Mean of the absolute values of the incremental strain components, } \\
\text { normalized by } \Delta \varepsilon_{z z} \text {, dimensionless }\end{array}$ \\
\hline$\sum \mid$ mean $/ \Delta \varepsilon_{z z} \mid$ & $\begin{array}{l}\text { Cumulative mean of the absolute values of the incremental strain } \\
\text { components, normalized by } \Delta \varepsilon_{z z} \text {, dimensionless }\end{array}$ \\
\hline
\end{tabular}

(Heap et al., 2017) to $90 \mu \mathrm{m}$ (Wong et al., 1997). Bentheim sandstone comes from an outcrop at Gildehausen quarry, near Bentheim, Germany (Klein et al., 2001). This sandstone is relatively homogeneous and composed of $95 \%$ quartz, $3 \%$ kaolinite and $2 \%$ orthoclase. The size of the quartz grains varies between 200 and $400 \mu \mathrm{m}$ (Schutjens et al., 1995; Van Baaren et al., 1990), with a mean grain size of $300 \mu \mathrm{m}$ (Ma and Haimson, 2016). The average porosity of this sandstone is $22.8 \%$ (Klein et al., 2001). Anstrude limestone is obtained from a quarry in Bierry-les-Belles-Fontaines, Burgundy, France. The limestone is an assemblage of $100-1000 \mu \mathrm{m}$ sized ooids (concentric spheres of calcite). Each ooid is made of micro-crystalline calcite with grain size finer than $4 \mu \mathrm{m}$, and in turn contains numerous small pores at micro to nano meter scale, making it highly porous (Lion et al., 2004). Sparite crystalline calcite makes the cement between the ooids. Mean porosity of this limestone is $19.9 \%$, close to $20 \%$ (Lion et al., 2004). Thus the porosities of our rocks range from $20 \%$ (Anstrude limestone) to 23\% (Bentheim sandstone and Adamswiller sandstone). We measured the porosity of the rock blocks from which samples were cored using a weighting approach (weighting the sample dry and then after complete water saturation 
Table 2

Experimental conditions for dynamic in-situ X-ray synchrotron imaging of triaxial compression tests on porous rocks

\begin{tabular}{|c|c|c|c|c|c|c|c|c|c|}
\hline Rock type & $\begin{array}{l}\text { True } \\
\text { porosity }\end{array}$ & $\begin{array}{l}\text { Initial } \\
\text { porosity } \\
(\mu \mathrm{CT}), \phi_{0} \\
(\%)\end{array}$ & $\begin{array}{l}\text { Confining } \\
\text { pressure, } \\
\sigma_{2}=\sigma_{3}\end{array}$ & $\begin{array}{l}\text { Pore } \\
\text { pressure, } p_{0}\end{array}$ & $\begin{array}{l}\text { Differential } \\
\text { stress at } \\
\text { yield, } \sigma_{d}^{y}\end{array}$ & $\begin{array}{l}\text { Differential } \\
\text { stress at } \\
\text { failure, } \sigma_{d}^{f}\end{array}$ & Temperature & $\begin{array}{l}\text { Rate of } \\
\text { increase in } \\
\text { differential } \\
\text { stress }\end{array}$ & $\begin{array}{l}\text { Number } \\
\text { of } 3 \mathrm{D} \\
\text { scans }\end{array}$ \\
\hline $\begin{array}{c}\text { Adamswiller } \\
\text { sandstone }\end{array}$ & $\begin{array}{l}\text { 23\% (Heap } \\
\text { et al., } \\
2017 \text { ) }\end{array}$ & 13.2 & $30 \mathrm{MPa}$ & 0 & $80 \mathrm{MPa}$ & $102 \mathrm{MPa}$ & $20^{\circ} \mathrm{C}$ & $\begin{array}{c}2 \mathrm{MPa} / \mathrm{step} \\
\text { (5 } \mathrm{MPa} \text { for } \\
\text { final step) }\end{array}$ & 54 \\
\hline $\begin{array}{l}\text { Bentheim } \\
\text { sandstone }\end{array}$ & $\begin{array}{l}22.8 \% \\
\quad \text { Klein } \\
\text { et al., } \\
2001)\end{array}$ & 16.7 & $5 \mathrm{MPa}$ & 0 & $66 \mathrm{MPa}$ & $76 \mathrm{MPa}$ & $23{ }^{\circ} \mathrm{C}$ & $1 \mathrm{MPa} / \mathrm{step}$ & 56 \\
\hline $\begin{array}{l}\text { Anstrude } \\
\text { limestone } \\
2\end{array}$ & $\begin{array}{l}20 \% \text { (Lion } \\
\text { et al., } \\
2004)\end{array}$ & 7.8 & $20 \mathrm{MPa}$ & 0 & $40 \mathrm{MPa}$ & $59 \mathrm{MPa}$ & $22^{\circ} \mathrm{C}$ & $5 \mathrm{MPa} / \mathrm{step}$ & 43 \\
\hline $\begin{array}{l}\text { Anstrude } \\
\text { limestone } \\
3\end{array}$ & $\begin{array}{l}20 \% \text { (Lion } \\
\text { et al., } \\
2004 \text { ) }\end{array}$ & 6.8 & $5 \mathrm{MPa}$ & 0 & $32 \mathrm{MPa}$ & $40 \mathrm{MPa}$ & $22{ }^{\circ} \mathrm{C}$ & $2 \mathrm{MPa} / \mathrm{step}$ & 26 \\
\hline $\begin{array}{l}\text { Anstrude } \\
\text { limestone } \\
4\end{array}$ & $\begin{array}{l}20 \% \text { (Lion } \\
\text { et al., } \\
2004 \text { ) }\end{array}$ & 15.6 & $20 \mathrm{MPa}$ & 0 & $51 \mathrm{MPa}$ & $66 \mathrm{MPa}$ & $23^{\circ} \mathrm{C}$ & $1 \mathrm{MPa} / \mathrm{step}$ & 55 \\
\hline $\begin{array}{l}\text { Anstrude } \\
\text { limestone } \\
5\end{array}$ & $\begin{array}{l}20 \% \text { (Lion } \\
\text { et al., } \\
2004)\end{array}$ & $3.5 \%$ & $5 \mathrm{MPa}$ & 0 & $36 \mathrm{MPa}$ & $42 \mathrm{MPa}$ & $23^{\circ} \mathrm{C}$ & $1 \mathrm{MPa} / \mathrm{step}$ & 43 \\
\hline $\begin{array}{l}\text { Anstrude } \\
\text { limestone } \\
6\end{array}$ & $\begin{array}{l}20 \% \text { (Lion } \\
\text { et al., } \\
2004 \text { ) }\end{array}$ & 6.3 & $30 \mathrm{MPa}$ & $10 \mathrm{MPa}$ & $56 \mathrm{MPa}$ & $125 \mathrm{MPa}$ & $22^{\circ} \mathrm{C}$ & $1 \mathrm{MPa} / \mathrm{step}$ & 114 \\
\hline
\end{tabular}

and calculating the porosity after assuming a grain density from mineral composition) and found values equal those already published in the literature (Table 2). However we did not measure the porosity of each single core sample used in the experiments.

The core samples had a height $(\sim 10 \mathrm{~mm})$ to diameter $(\sim 5 \mathrm{~mm})$ ratio of $2: 1$. For each experiment, we inserted the specimen into a jacket made of Viton fluoropolymer elastomer and then inserted this assembly into the triaxial deformation apparatus. Experiments were performed at ambient temperature $\left(20-23{ }^{\circ} \mathrm{C}\right)$, under a constant confining pressure $\left(\sigma_{2}=\sigma_{3}\right)$ applied by silicon oil on the jacket that surrounded the sample. During the experiments we verified on the X-ray images that the jacket was always in tight contact with the sample and we consider that if the jacket had an effect on sample deformation, this effect is similar between experiments and constant during each experiment. Each sample was placed axially between two stainless steel pistons and the interface contacts were not lubricated. The lower piston was held fixed and samples were loaded axially $\left(\sigma_{1}\right)$ in steps of 1-5 MPa applied on the upper piston, until failure occurred. For experiment on sample Anstrude \#6, we injected water as a pore fluid with a constant fluid pressure of $10 \mathrm{MPa}$ (Table 2). Due to the loading conditions (imposed stress steps), the pump controlling the axial stress was operating even after the stress drop that occurred at brittle failure, which prevented to stop the experiment exactly when the main brittle event occurred. The ambient temperature in the room was in the range $22-24{ }^{\circ} \mathrm{C}$.

The Hades apparatus is installed on the rotating stage of the X-ray microtomography beamline ID19 at the European Synchrotron Radiation Facility (Grenoble, France). A synchrotron polychromatic $\mathrm{X}$-ray beam with a maximum energy of $200 \mathrm{keV}$ was sent through the apparatus. Due to X-ray attenuation from the walls of the Hades apparatus made of 
titanium, the average X-ray energy absorbed by the sample was around $89 \mathrm{keV}$. During each scan, the stage of the beamline was rotated from $0^{\circ}$ to $+180^{\circ}$ and back to $0^{\circ}$ while stress was maintained constant. Each scan lasted around $90 \mathrm{~s}$ and a series of 2500 two-dimensional radiographs of the three-dimensional sample were recorded. Each experiment was stopped when a significant stress drop was measured, corresponding to the brittle failure of the sample. Between 26 and 144 tomograms were acquired for each sample.

\subsection{Tomogram Reconstruction and Segmentation}

The radiographs acquired at beamline ID19 were processed to reconstruct three-dimensional tomograms $(1600 \times 1600 \times 1600$ voxel $)$ using the plain filtered back-projection method employed in the program PyHST2 (Mirone et al., 2014), with a single-distance phase-retrieval algorithm adapted from Paganin et al. (2004). The voxel size in the tomograms was $6.5 \mu \mathrm{m}$. The spatial resolution was not measured here but, on beamline ID17 with similar optical systems as beamline ID19, a spatial resolution of the order of $20 \mu \mathrm{m}$ was measured (Mittone et al., 2017). After reconstructing the volumes (Fig. S1), we did not observe blurring that would indicate movements of the sample or fracture growth during scan acquisition. We computed the axial strain as a function of applied stress by measuring the axial length of the sample directly on the three-dimensional X-ray tomograms (e.g., Renard et al., 2018, 2019a). Segmentation of tomograms incorporate corrections for (1) the fluctuations in synchrotron X-ray intensity, (2) beam hardening, (3) ring artifacts and (4) other false projections. We reduced the noise in the data by using a non-local means filter (Buades et al., 2005). Then, based on the intensity of the histogram of each tomogram, we separated the voxels into two classes: the rock matrix, and pore space/ fractures (Renard et al., 2019a). The same grey level threshold was applied in all the tomograms of a given experiment (Fig. S2). Segmentation of the tomograms provides an estimate of the initial porosity, $\phi_{\mathrm{o}}$, at the spatial resolution of the images (Table 2). Because the samples are heterogeneous and may contain a bimodal porosity (Anstrude limestone), and because the porosity extracted on the tomograms is limited by the spatial resolution, the initial micro-computed tomography porosities, $\phi_{0}$, reported in Table 2 are smaller than the actual porosities of the rock samples. It varies also among the Anstrude limestone samples because of a different concentration of macropores between these samples. For all samples, the porosity at the differential stress of system size failure was smaller than the initial porosity (Fig. S3).

To calculate the local mean porosity from the segmented tomograms, we divided the rock volume into sub-volumes of size equivalent to twice the grain size of the respective rock. The mean grain size of Adamswiller sandstone is near $120 \mu \mathrm{m}$ (Heap et al., 2017) and Bentheim sandstone is $300 \mu \mathrm{m}$ (Ma and Haimson, 2016). Anstrude limestone grain size is approximated to $100 \mu \mathrm{m}$, which is the size of smallest ooid (Lion et al., 2004). We have then computed the porosity in each sub-volume for each experiment. We have then obtained mean value of these local porosity values at every strain step in the experiment. Mean porosity is plotted as a function of increasing strain in Figs. 8, S6, S8. We performed this calculation to compare the calculated porosity to the local strain computed from digital volume correlation. To conclude, using these subvolumes, one can compare the local strain increments in the sample with the local porosity evolution.

\subsection{Digital Volume Correlation Analysis}

The digital volume correlation analysis calculates fields of local 3D incremental strain tensors between two 3D volumes. We applied this technique to quantify incremental strain evolution between pairs of 3D tomograms acquired in the experiments. We employed the software TomoWarp2 (Tudisco et al., 2017), following procedures described in McBeck et al. (2018) and Renard et al., (2019a, 2019b). We divided each experiment into eight to ten nearly equal intervals of macroscopic axial strain $\left(\Delta \varepsilon_{z z}\right)$, as shown in Fig. S4 and then calculated digital volume correlation on the pairs of tomograms acquired at those equally-spaced macroscopic axial strains. The digital volume correlation algorithm divides each 3D tomogram into sub-volumes, with a node spacing and size of the correlation window of 20 voxels, 
producing a spatial sampling of $130 \mu \mathrm{m}$. The choice of 20 voxels comes from two constraints. One the one hand, the size of the subvolume is large enough such that 1-2 grains are contained in the subvolumes, allowing to perform the digital correlation calculation with enough texture in each subvolume. On the other hand, the size of the subvolume is small enough such that we can identify zones where localization of deformation occurs inside the sample. We have tested correlation windows of 15 to 30 voxels, without significant differences for the main conclusions of the study. We used search window sizes of $\pm 10, \pm 15$ or \pm 50 voxels, depending on the magnitude of the macroscopic axial strain obtained between the tomogram pair. The search window size determines the maximum detected displacement magnitudes, and so larger changes in the macroscopic axial strain require larger search window sizes. We choose the coordinate system such that the direction of the maximum compression is along the $\mathrm{z}$ axis.

For each experiment, we first computed the threedimensional incremental displacement $(\overleftrightarrow{u})$ field between each pair of tomograms. From the displacement fields, we calculated the components of the incremental strain tensor. Throughout the sub-volumes, we computed the components of incremental displacement, such that negative divergence $(\nabla \cdot \overleftrightarrow{u}<0)$, positive divergence $(\nabla \cdot \overleftrightarrow{u}>0)$, negative rotation (also called curl, $\nabla \times \overleftrightarrow{u}<0$ ) and positive rotation $(\nabla \times \overleftrightarrow{u}>0)$ indicate the contractive strain, dilative strain, left-lateral local rotation and right-lateral local rotation, respectively. Explicit mathematical equations for each of the strain components are given in Table 1. Here we use the curl values, which indicate local rotations in subvolumes of the sample, as a proxy for shear strain. Note also that positive and negative curls (corresponding to right- and left- lateral shear strain) depend on the reference frame of the sample which is here the tomography stage of the synchrotron.

In our previous studies, we have used two different methods to post-process digital volume correlation incremental displacement data acquired with Tomowarp2. In earlier studies (McBeck et al., 2018; Renard et al., 2019a), we have post-processed the digital volume correlation data by calculating the local strain tensors. We calculated the first invariant of the incremental strain tensor $\left(\mathrm{I}_{2}\right.$, equal to the divergence of the incremental displacement field divided by three) and also various metrics indicative of shear strain: either the second invariant of the incremental strain tensor $\left(\mathrm{I}_{1}\right)$ or the Von Mises strain $\left(\sqrt{3 J_{2}}\right)$, see Table 1 . In more recent studies (McBeck et al., 2019b, 2020; Renard et al., 2019b), we have decomposed the incremental displacement field into its volumetric (divergence) and rotational components (curl). This step was inspired by the geodetic scientific community where GPS displacement fields are decomposed using this technique (see for example Bos et al. (2003) and Bennett et al. (2003) who both use the curl component). To allow readers to compare the results of the present study with our previous studies we now present both the decomposition of the digital volume correlation displacement fields into divergence/curl (Figs. 5, 6, 7) and strain invariant $I_{1}$ and Von Mises strain, $\sqrt{3 J_{2}}$ (Figs. S6-S8).

From the population of incremental divergence and curl components within each rock volume (Figure S5), we computed the mean of the local divergence and curl values normalized by the amount of axial strain increment $\left(\Delta \varepsilon_{z z}\right)$ at every digital volume correlation step, $\mid$ mean $/ \Delta \varepsilon_{z z} \mid$. These calculated divergence and curl values are used to measure incremental measurements of the strain accumulated between the acquisitions of the two tomogram pairs used in the analysis (Fig. S4). In order to compare these incremental strain values to the porosity, which is a cumulative measure, we also computed a cumulative measure of the incremental strain components, $\sum \mid$ mean $/ \Delta \varepsilon_{z z} \mid$ (Figs. S6 to S8).

\subsection{Scanning Electron Microscopy Imaging}

Most samples, when removed from the rig, were highly damaged and mostly in powder form. However, for the Adamswiller sandstone and Anstrude limestone \#2, \#4, \#5 samples, the cores could be recovered after the experiment for post-mortem observations. These four samples were impregnated with epoxy resin to consolidate them and then cut along the vertical axis of the cylinder. For two of them, only a small fraction of the sample could be recovered (Anstrude \#2 and \#5). The surfaces were polished with several sandpapers with increasing grit, 
from \#320 to \#4000, and then carbon coated. SEM backscatter images of two samples were acquired on a Hitachi SU5000 field-emission scanning electron microscope (FE-SEM) at the Department of Geosciences, University of Oslo.

\section{Results}

\subsection{Macroscopic Mechanical Deformation}

We observed two modes of brittle compressive failure in porous rocks in this study. The sandstones
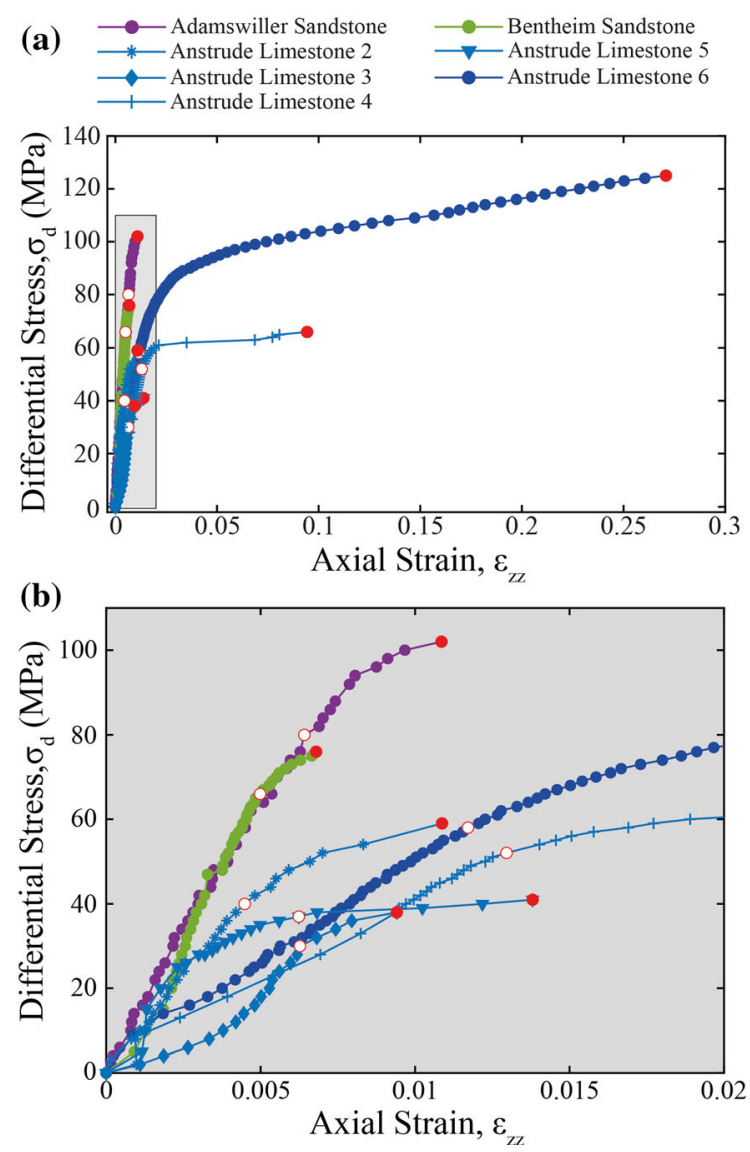

Figure 1

Relationships between differential stress and axial strain in seven experiments on porous rocks: Adamswiller sandstone, Bentheim sandstone, and Anstrude limestone $(2,3,4,5,6)$. Table 2 shows the experimental conditions. (a) The complete differential stress versus axial strain relationships. (b) Close up of relationships for the domain shown in the gray rectangle in (a). Open and closed red circles indicate the yield point and last scan before sample-size failure, respectively. Each circle shows the mechanical conditions of a 3D microtomography scan experiments and limestones at low confinement (Anstrude \#3, \#5) failed after a short yielding phase and a small amount of accumulated macroscopic axial strain (Fig. 1). In contrast, one limestone under higher confinement (Anstrude \#4) and another one with pore pressure (Anstrude \#6) failed with longer yielding phases. The sample Anstrude \#2, under higher confinement, had a shorter yield phase than Anstrude \#4. However, sample Anstrude \#2 had a lower macroporosity than the sample Anstrude \#4, which could explain this difference in yield phase.

At low differential stress, $\sigma_{d}=\sigma_{1}-\sigma_{2}$ $=\sigma_{1}-\sigma_{3}$, the axial strain increased quasi-linearly with increasing differential stress, in the macroscopic linear regime. We identified the differential stress at the yield point, $\sigma_{d}^{y}$, when the differential stress versus strain curve deviated by $3 \%$ from linearity (e.g., Brace et al., 1966). The yield point occurred at 70$80 \%$ of the differential stress at failure, $\sigma_{d}^{f}$, for all the samples except for Anstrude limestone \#6, where it was $40-45 \%$ of $\sigma_{d}^{f}$ (Table 2). Further increase in the differential stress resulted in irreversible accumulation of macroscopic contraction in the core until $\sigma_{d}^{f}$, when the sample failed with a sudden stress drop, and slip along several faults. We have observed a stress drop for all the brittle compression experiments, which occurs less than one MPa differential stress beyond the last tomogram acquired (red circle in Fig. 1).

The total accumulated axial strain at failure in the sandstone experiments (0.006-0.011) was less than the Anstrude limestone experiments (0.011-0.27). The Bentheim sandstone accumulated the least macroscopic axial contraction of all the experiments (0.006). This sandstone subjected to $\sigma_{3}=5 \mathrm{MPa}$ may have hosted less contraction than the Adamswiller sandstone $\left(\sigma_{3}=30 \mathrm{MPa}\right)$ due to the lower applied confining stress. The five experiments on Anstrude limestone host a wider range of cumulative axial strain than the two sandstone experiments. The initial difference of macroporosity, the application of $10 \mathrm{MPa}$ water fluid pressure in one of the limestone experiments, and the resulting large accumulation of axial contraction relative to the other experiments, produce this wider range in the limestone experiments. 


\subsection{Microstructural Changes and Evolution Of Porosity Towards Failure}

Macroscopic deformation in each rock core occurs by deformation of pores and grains at microscopic scale, giving rise to a change in microstructure. Our experimental setup provides access to the deformation microstructure with 6.5 $\mu \mathrm{m}$ sampling distance. We segmented the pore space and rock matrix in each individual tomogram for each experiment until sample-size failure. Figures 2 and 3 show the microstructural changes including porosity variation in Adamswiller sandstone and Anstrude limestone \#6, respectively. In the Adamswiller sandstone experiment, the $\mathrm{x}-\mathrm{Z}$ (vertical) cross-sections of the tomograms show a reduction in pore space at the yield stress (Fig. 2b). The density of pore space post-yield (Fig. 2b-iii) appears larger than that at yield (Fig. 2b-ii). In the Anstrude limestone \#6 experiment, the rock core compacted as the pore space decreased. Then, fracture coalescence characterized macroscopic failure (Fig. 3f). Tomograms and 2D slices of Adamswiller sandstone, Bentheim sandstone and Anstrude limestone \#6 are also displayed in Figures $\mathrm{S} 1$ and $\mathrm{S} 2$.

To quantify the porosity evolution that resulted in the observed sample compaction, we computed the volume of pore space in each rock core throughout
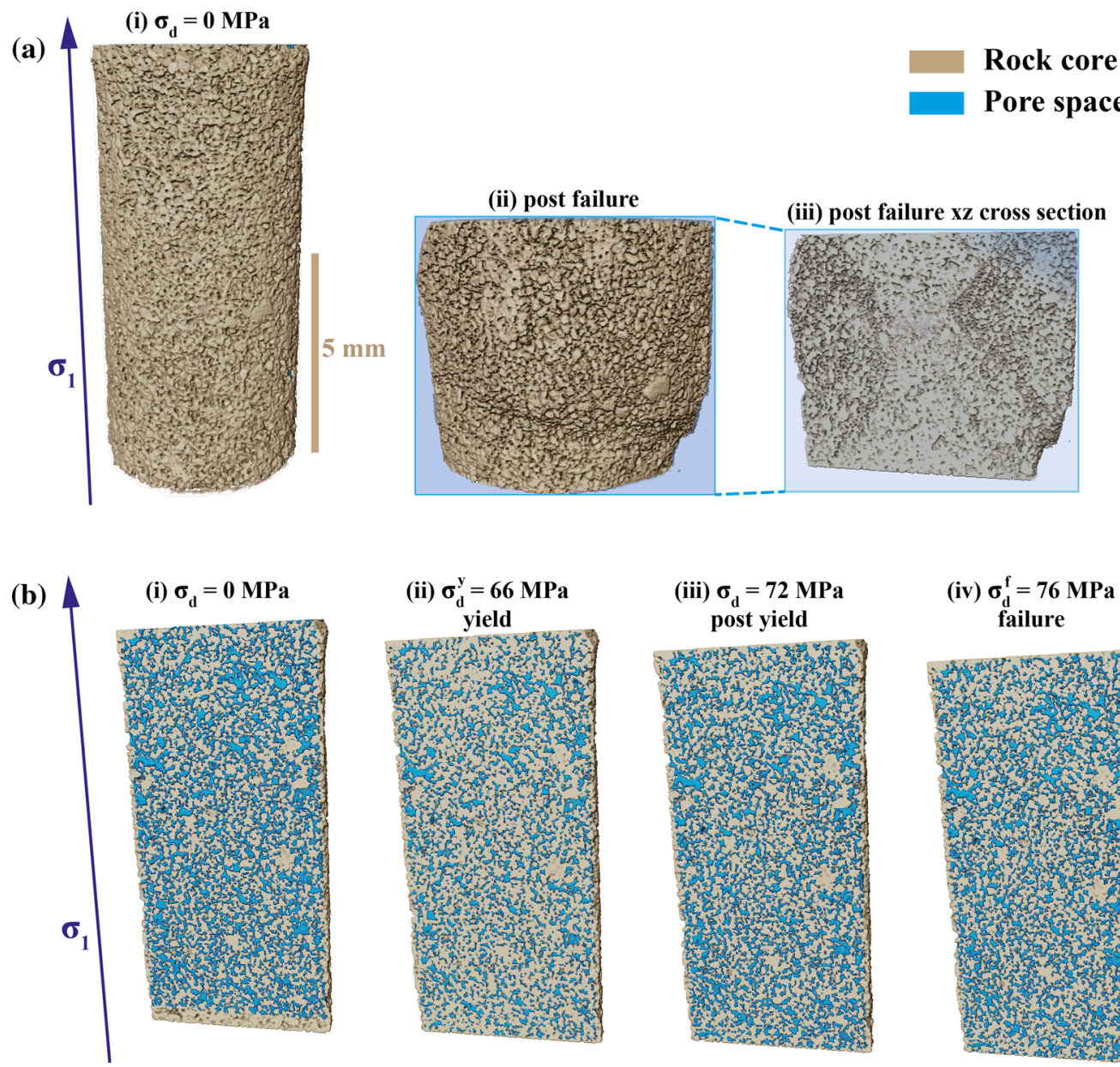

(iv) $\sigma_{\mathrm{d}}^{\mathrm{f}}=76 \mathrm{MPa}$ failure

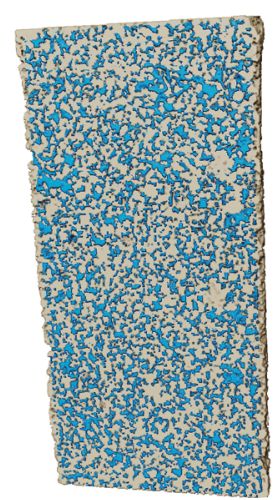

Figure 2

Rendering of the microstructural evolution of pore space in Bentheim sandstone imaged by X-ray microtomography. a Rock microstructure at the initial (i) and final stage (ii) of the experiment. (iii) Axial cross-section of post-failure rock core. $\mathbf{b}$ Cross-sections of pore space for an $\mathrm{x}-\mathrm{Z}$ cross section at (i) initial, (ii) yield, (iii) post yield and (iv) just before failure stages, where the porosity is represented in blue 

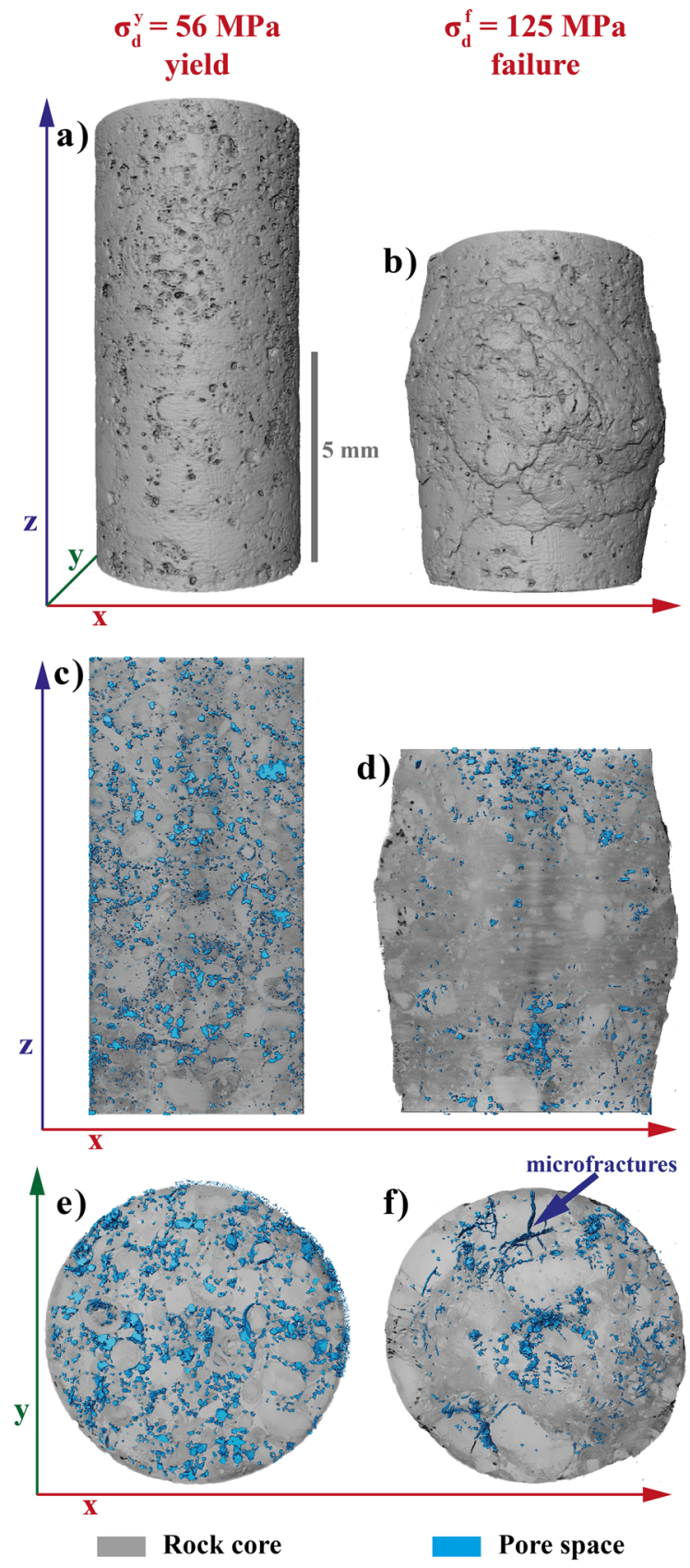

Figure 3.

3D pore microstructure at yield and just before the final failure in Anstrude limestone 6 sample. a, b 3D rock core surface. $\mathbf{c}-\mathbf{f}$ Cross sections. The pore space is shown in blue

loading (Fig. S3). To compare the variation in porosity from the beginning to the end of each experiment, we calculated a measure of the relative variation in porosity. We computed the porosity parameter, $D_{\phi}=\frac{\phi-\phi_{0}}{1-\phi_{0}}$, similar to previous studies
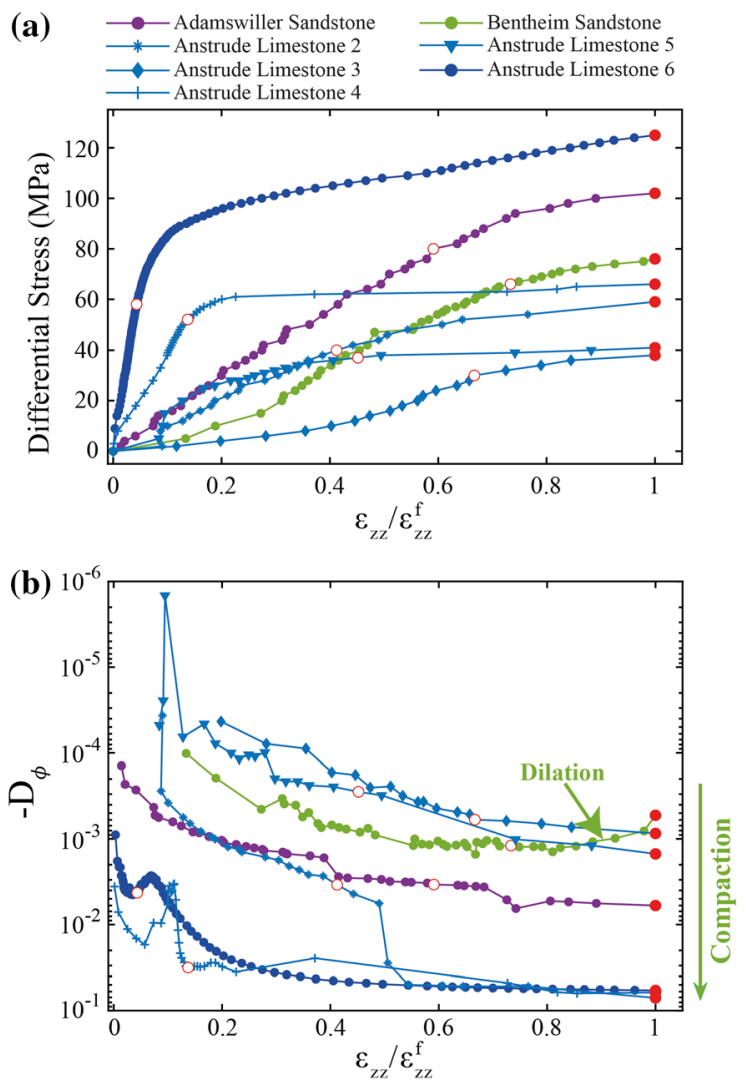

Figure 4

a Differential stress versus macroscopic axial strain, $\varepsilon_{z z}$, normalized by the axial strain at failure, $\varepsilon_{z z}^{f}$. b Dimensionless porosity parameter, $D_{\phi}=\left(\phi-\phi_{0}\right) /\left(1-\phi_{0}\right)$ relative to $\varepsilon_{z z} / \varepsilon_{z z}^{f}$ shown in semi-log scale and reversed axis. Increasingly negative values indicate increasing compaction. The open and filled circles show the yield point and last scan before failure, respectively. The arrow points to an increase of dilation, after a phase of compaction, in the Bentheim sandstone when approaching failure

(Kandula et al., 2019; Renard et al., 2018). The rationale behind the normalization by $\left(1-\phi_{0}\right)$ is that this parameter allows comparing samples with different initial porosities, where $\phi_{0}$ is the initial porosity and $\phi$ is the porosity at a given stress step. Positive $D_{\phi}$ indicates sample dilation and negative $D_{\phi}$ indicates compaction. On Fig. $4 \mathrm{~b}$ where the vertical axis is logarithmic, we report $-D_{\phi}$, because samples compacted, as a function of normalized axial strain, $\varepsilon_{z z} / \varepsilon_{z z}^{f}$.

The porosity of all the rock cores decreases nonlinearly towards failure, indicating compaction. This decrease is rapid for Anstrude limestones \#2, \#4, and $\# 6$, which are subjected to higher confining pressures 
$\left(\sigma_{3}=20-30 \mathrm{MPa}\right)$. For sample Anstrude \#2, axial strain-porosity curve shows a sharp drop at $\varepsilon_{z z} / \varepsilon_{z z}^{f}=0.5$, post yield. For sample Anstrude \#5, a sharp drop is observed at $\varepsilon_{z z} / \varepsilon_{z z}^{f}=0.15$. Sample Anstrude \#4 shows a sharp peak and drop at $\varepsilon_{z z} / \varepsilon_{z z}^{f}=0.1$, before yield. Sample Anstrude \#6, which was subjected to pore fluid pressure, shows a smooth continuous decrease in porosity with a small peak near yield $\left(\varepsilon_{z z} / \varepsilon_{z z}^{f}=0.1\right)$. Similar to the limestone experiments, the Adamswiller sandstone shows a continuous non-linear decrease in porosity. In contrast, the Bentheim sandstone shows increasing porosity post yield. Thus, for this sample, the porosity first decreased until the yield point at $\varepsilon_{z z} / \varepsilon_{z z}^{f}=0.75$, and then increased until failure.

\subsection{Computation of Accumulated Strain Toward Failure}

Using the digital volume correlation method detailed in Sect. 3.3, we have computed the incremental divergence and curl components. We display three-dimensional views of the variations of these components as a function of applied axial strain, which facilitates the evaluation of the dominant failure mechanism guiding the deformation for each sample. Figures 5 and 6 show the 95th percentile of the incremental divergence and curl component populations at low and high $\varepsilon_{z z} / \varepsilon_{z z}^{f}$ for two samples: Bentheim sandstone and Anstrude limestone \#6. The supplementary movies V1-V7 show time-lapse evolutions of these populations whereas the movies V7V14 show similar data where the first invariant of the incremental strain tensor and the Von Mises incremental strain are reported. These digital volume correlation calculations show that the high values of incremental divergence and curl and strain populations tend to localize near failure (Figs. 5, 6). For example, conjugate bands of higher magnitude strain formed in the Anstrude limestone \#6 near failure (Fig. 6e-h). When $\varepsilon_{z z} / \varepsilon_{z z}^{f}$ is close to zero, the higher strain values are spread throughout the rock. When approaching $\varepsilon_{z z} / \varepsilon_{z z}^{f}=1$, the high strain values appear more localized. In all of the experiments, the strain

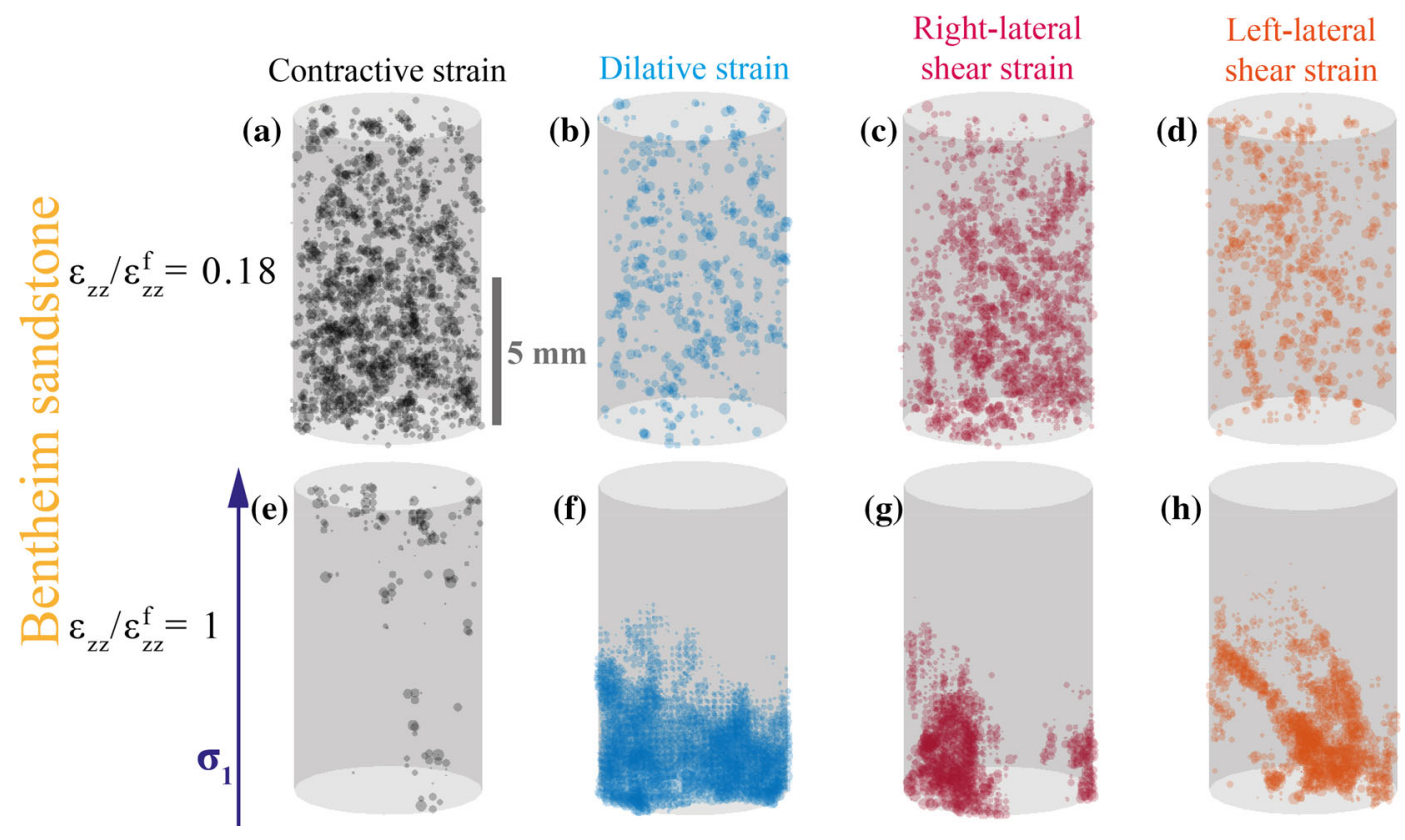

Figure 5

High values of 3D incremental divergence and curl components at low and high macroscopic axial strains for the experiment on Bentheim sandstone. Circles show the values $>95$ th percentile of each population. The columns show the contractive (a, e), dilative (b, f), right-lateral curl $(\mathbf{c}, \mathbf{g})$ and left-lateral curl $(\mathbf{d}, \mathbf{h})$. Top and bottom rows show the population fields when $\varepsilon_{z z} / \varepsilon_{z z}^{f}=0.18$ and $\varepsilon_{z z} / g_{z z}^{f}=1$, respectively. The size of each marker is proportional to the magnitude of divergence and curl 


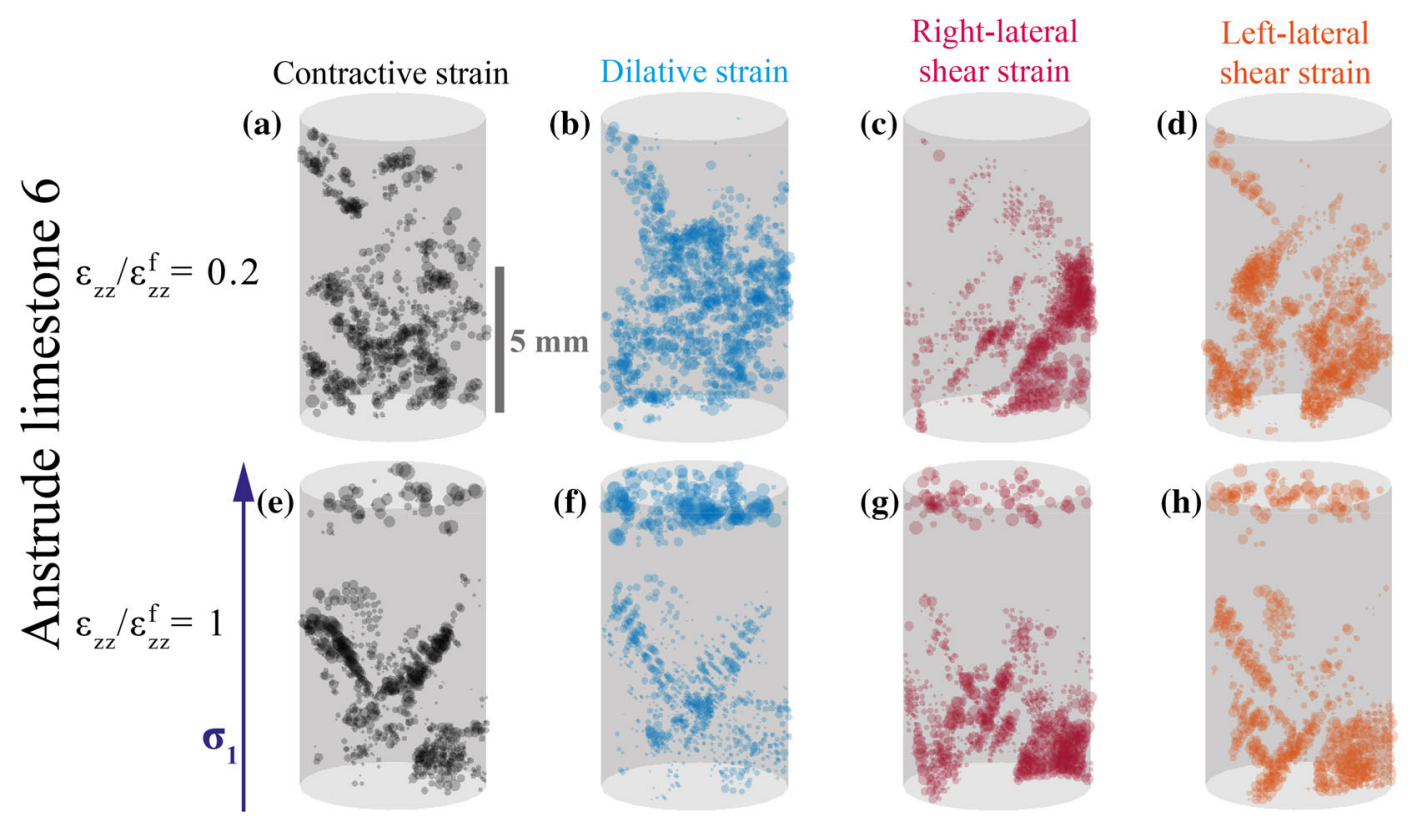

Figure 6

High values of 3D incremental divergence and curl components at low and high macroscopic axial strains for the experiment on Anstrude limestone \#6. Circles show the values $>95$ th percentile of each population. The columns show the contractive (a, e), dilative (b, f), rightlateral curl $(\mathbf{c}, \mathbf{g})$ and left-lateral curl $(\mathbf{d}, \mathbf{h})$. Top and bottom rows show the population fields when $\varepsilon_{z z} / \varepsilon_{z z}^{f}=0.18$ and $\varepsilon_{z z} / \varepsilon_{z z}^{f}=1$, respectively.

The size of each marker is proportional to the magnitude of divergence and curl

components indicate localization of damage towards failure (Figs. 5, 6; Movies V1-V7). In Bentheim sandstone (Fig. 5), the contractive strain is diffusely spread throughout the rock core at $\varepsilon_{z z} / \varepsilon_{z z}^{f}=0.18$ and at failure $\left(\varepsilon_{z z} / \varepsilon_{z z}^{f}=1\right)$. Conversely, the dilative strain is spread at $\varepsilon_{z z} / \varepsilon_{z z}^{f}=0.18$ and then localizes at failure. Similar to the dilative strain (divergence), the curl components, a proxy for shear strain, show localization towards failure. In the 3D incremental strain components, the zones of high dilation and compaction do not exactly match the zones of high shear in all the experiments.

To compare the dominance of the various strain components when approaching failure, we show the magnitude of the mean incremental contraction (negative divergence), dilation (positive divergence), and curl throughout loading in each experiment. We divide each incremental component by the amount of macroscopic axial contraction, $\Delta \varepsilon_{z z}$, that occurs between pairs of tomograms used in the digital volume correlation calculations to ensure that the magnitude of $\Delta \varepsilon_{z z}$ does not strongly influence the relative magnitudes of the means. Figure 7 thus shows the mean of each component divided by $\Delta \varepsilon_{z z}$, $\mid$ mean $/ \Delta \varepsilon_{z z} \mid$. For the sandstone experiments, the means of the incremental divergence and curl indicate that the micromechanisms guiding deformation shift from contraction to dilation post yield (Adamswiller) or near yield (Bentheim). In contrast, the five cores of Anstrude limestone show three different behaviors. The dominant failure mechanism guiding sample Anstrude \#2 is contraction. For samples Anstrude \#3 and \#4, contraction dominates deformation until close to failure, when dilation dominates. For samples Anstrude \#5 and \#6, dilation dominates deformation throughout the experiment.

For Adamswiller sandstone, the dominant mechanism guiding deformation shifts from contraction to dilation at $\varepsilon_{z z} / \varepsilon_{z z}^{f}=0.7$ (post yield), and continues until failure (Fig. 7a). For Bentheim sandstone (Fig. 7b), the dilative incremental strain accelerates between the yield point and failure. At $\varepsilon_{z z} / \varepsilon_{z z}^{f}=0.9$ near failure, the shear strain dominates contraction. For sample Anstrude 2\#, all three components of incremental strain show a continuous increase up to failure (Fig. 7c). Contraction dominates throughout 


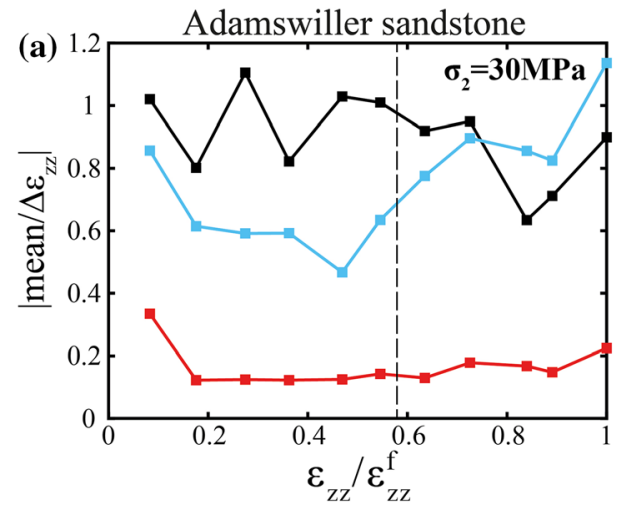

$\longrightarrow$ - Incremental contractive strain

_- Incremental dilative strain

—- Incremental shear strain

-_-_- Yield point
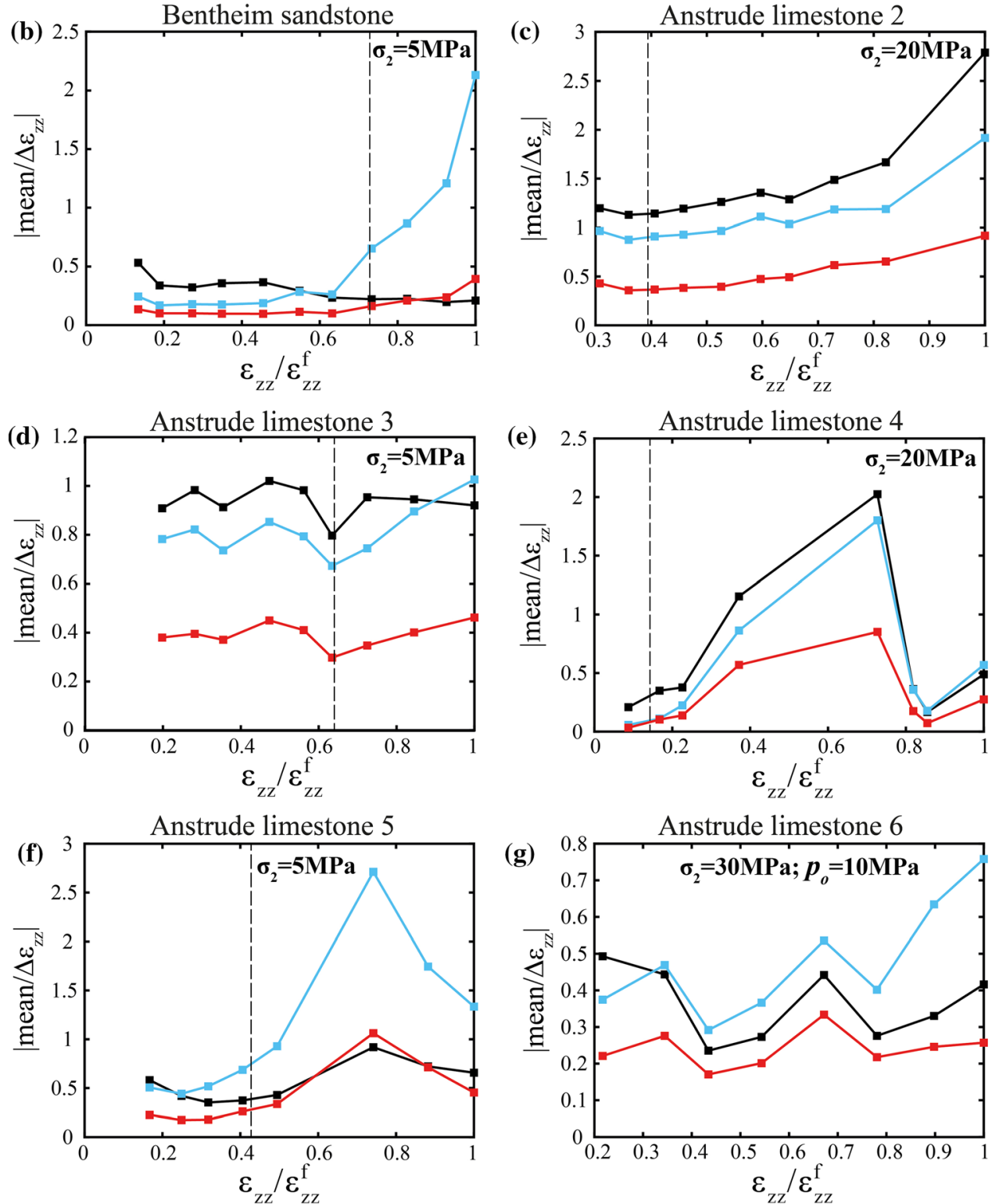
Figure 7

a-g Mean of the absolute values of the incremental divergence (contraction, dilation) and curl (a proxy for shear strain) components. Mean value of each component is normalized by the amount of macroscopic axial contraction, $\Delta \varepsilon_{z z}$, that occurs between scans used in the digital volume correlation calculations

loading. Deformation in samples Anstrude \#3 and \#4 (Fig. 7d, e) is dominated by contraction until $\varepsilon_{z z} / \varepsilon_{z z}^{f}=0.9$, when dilation exceeds contraction. For sample Anstrude \#4, the mean values of all the three incremental strain components show a peak at $\varepsilon_{z z} / \varepsilon_{z z}^{f}=0.7$ (Fig. 7e). Similarly, in sample Anstrude \#5, a peak in strain occurs at $\varepsilon_{z z} / \varepsilon_{z z}^{f}=0.75$ (Fig. 7f), as dilation dominates deformation. In general, three of the limestone experiments are dominated by contraction throughout the majority of the loading (samples Anstrude \#2, \#3, and \#4), while two are dominated by dilation (samples Anstrude \#5 and \#6). Both sandstones are dominated by dilation following yielding and near failure.

\subsection{Linking Porosity Variation with Incremental Strain Evolution}

Our X-ray tomography data enable tracking the macroporosity (i.e. porosity segmented from X-ray data, which is smaller than the actual porosity, see Table 2) and local strain field simultaneously. In order to characterize the strain localization mechanisms guiding the porosity evolution, we compare the bulk macroporosity calculated from the tomograms and the local divergence and curl components calculated from digital volume correlation. In Fig. 8, we show the cumulative means of respective components as a function of scaled axial strain, $\varepsilon_{z z} / \varepsilon_{z z}^{f}$, for all experiments, $\sum \mid$ mean $/ \Delta \varepsilon_{z z} \mid$. The mean value of porosity obtained from image segmentation at every step of axial step increase is described in Sect. 3.2 and shown on Fig. S2.

For all the experiments except the Bentheim sandstone, the mean porosity decreases while the cumulative incremental divergence and curl components increase towards failure (Fig. 8). In the Adamswiller sandstone experiment, the mean porosity decreases in steps and then drops following the yield point, at $\varepsilon_{z z} / \varepsilon_{z z}^{f}=0.75$ (Fig. 8a). All the divergence and curl components show an approximately linear increasing trend, indicating constant rates of strain accumulation. The contraction tends to increase the fastest, while the dilation and curl components increase at slower rates. This dominance of local contraction agrees with the decreasing porosity with loading. In the Bentheim sandstone experiment (Fig. 8b), the mean porosity decreases non-linearly and then stays at similar levels near the yield point. Then, above $\varepsilon_{z z} / \varepsilon_{z z}^{f}=0.8$, the porosity increases rapidly up to failure. These trends in the porosity agree with the evolution of the divergence and curl fields: the dilation remains below the contraction until $\varepsilon_{z z} / \varepsilon_{z z}^{f}=0.8$ and then the dilation increases rapidly preceding failure (Fig. 8). The samples of Anstrude limestone \#2, \#3, and \#4 (Fig. 8c-e) show similar trends in the evolution of cumulative contraction, dilation and shear components. All of the three cumulative components increase non-linearly. Contraction dominates deformation rather than dilation or shear strain. Consistent with these strain evolutions, porosity decreases with loading in all three experiments.

The relationships between the porosity and cumulative divergence and curl evolutions differ between the Anstrude limestone samples \#5 and \#6 (Fig. 8f, g) and the other Anstrude limestone experiments. The porosity of the Anstrude limestone samples \#5 and \#6 decreases with loading, similar to the other experiments. However, these experiments differ from the others because the mean cumulative dilation tends to be slightly higher than the mean cumulative contraction throughout loading in these experiments. While the decreasing porosity indicates that contraction should dominate deformation, the digital volume correlation data indicate that dilation dominates deformation in these two limestone experiments. Figure S6 provides a summary of evolutions of the differential stress, mean porosity, and cumulative and incremental dilation, compaction, and curl means for three different rock types subjected to low and high confinement.

We compare variations in strain invariants with porosity evolutions. Figure S7 summarizes the variation in the mean values of strain invariants namely, dilative and contractive volumetric strain $\left(I_{1}\right)$ and 

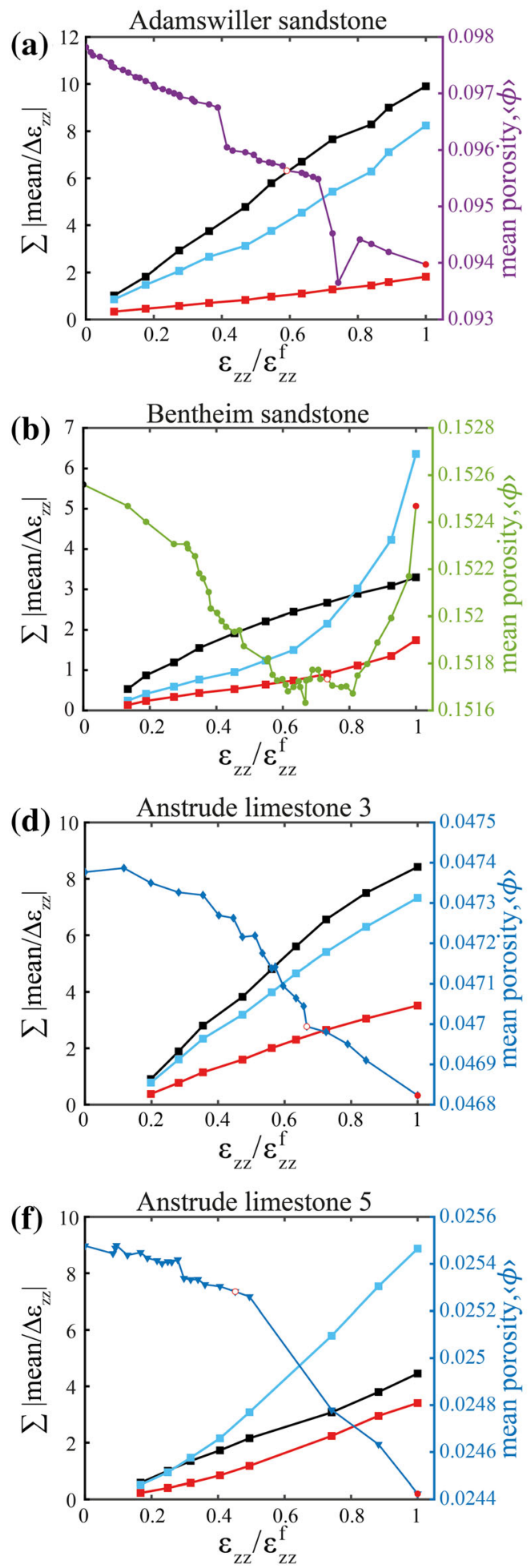
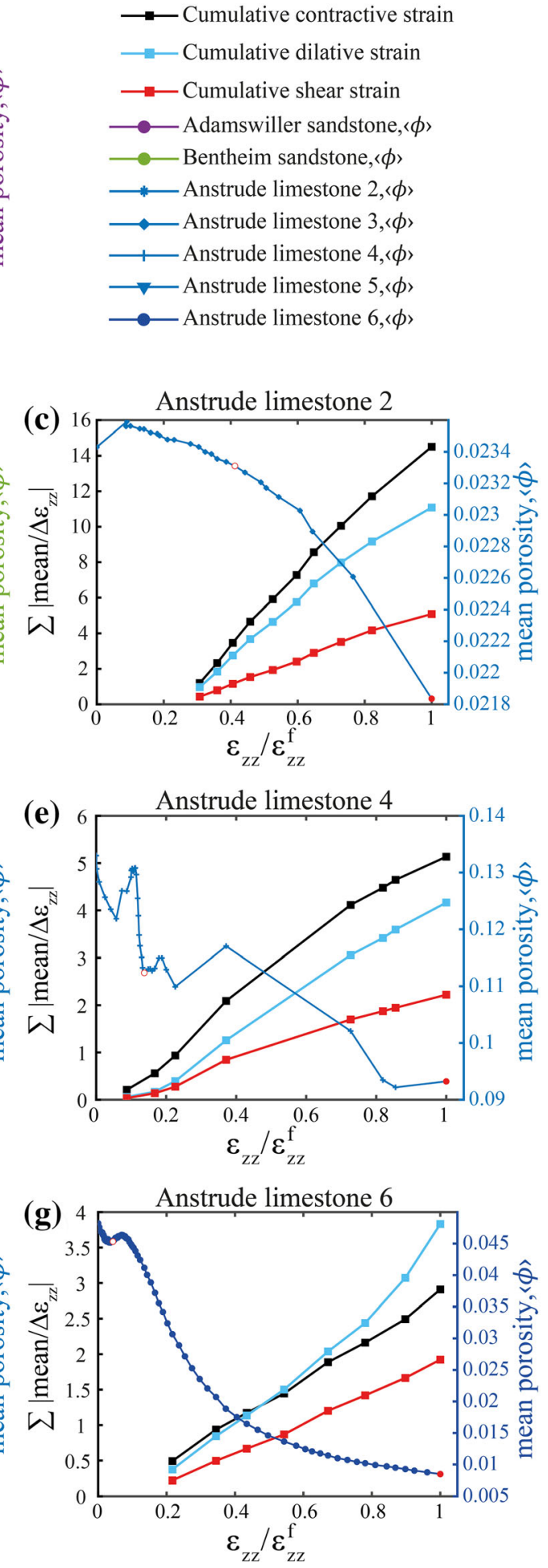
Figure 8

(a-g) Evolution of the cumulative local divergence (dilation is positive divergence, contraction is negative divergence) and curl (a proxy for shear strain) components and porosity. The cumulative local divergence and curl components are shown as the sum of the Imean $/ \Delta \varepsilon_{z z}$ I from previous digital volume correlation calculations, i.e., the cumulative mean. In general, porosity decreases as the magnitudes of these components increase. The exception to this trend is the Bentheim sandstone experiment (b), which hosts an increase of porosity (i.e. dilation) from the yield point until failure

Von Mises strain $\left(3 \sqrt{J_{2}}\right)$. Whereas Figure S8 shows the mean porosity evolutions in relation to the cumulative mean of strain invariants (dilative and contractive volumetric strain and Von Mises strain, in Figure S7, the mean value of Von Mises strain clearly dominates the volumetric strain. On the one hand, in a sandstone deformed at a higher confinement (Adamswiller-30 MPa), increasing trend in Von Mises strain correlates to decreasing mean porosity. On the other hand, at lower confinement (Bentheim$5 \mathrm{MPa}$ ), increasing trend in Von Mises strain correlates to increasing mean porosity.

\subsection{Post Failure Microstructure}

In order to provide further insights into the deformation mechanisms operating within these porous rocks, we imaged the microstructure of four samples post failure using scanning electron microscopy. Electron backscatter images of Adamswiller sandstone (Fig. 9) and Anstrude limestone sample \#4 (Fig. 10) show compaction shear bands, with pore collapse, grain crushing and formation of transgranular microfractures. Figures S9 and S10 display additional images of Anstrude limestone samples \#2 and \#5.

In Adamswiller sandstone, damage localization occurs along compaction shear bands located near one end of the sample. These regions (Fig. 9b, c) host grain comminution and pore space reduction. This observation is in agreement with the observed overall reduction of total porosity (Fig. 4) and dominance of compaction rather than dilation (Fig. 8). The total porosity decreases towards failure. The cumulative mean of the contractive strain (Fig. 8a) is higher than cumulative dilation throughout the experiment. The porosity evolution, strain fields, and microstructures indicate that this sandstone sample deformed via porosity reduction and diffuse compaction at lower differential stress, and then more localized compaction and shear with grain crushing, grain comminution, and transgranular fractures at higher differential stress when approaching failure.

All the limestone samples show regions of localization in the form of shear bands characterized
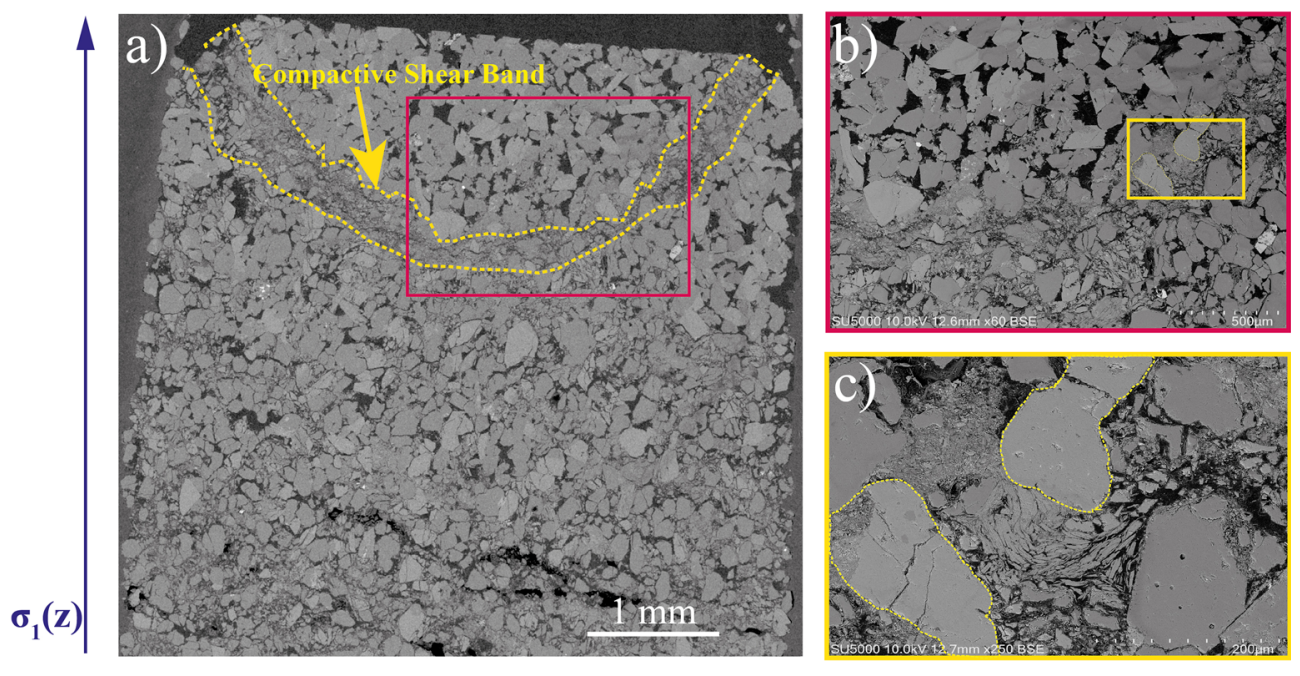

Figure 9

Scanning electron micrograph of a thin section of the Adamswiller sandstone sample after failure. a Compaction shear bands. b Close up of area in (a). c Close up of area in (b). Grains appear comminuted and crushed. Development of intra granular fractures is evident in (c) 

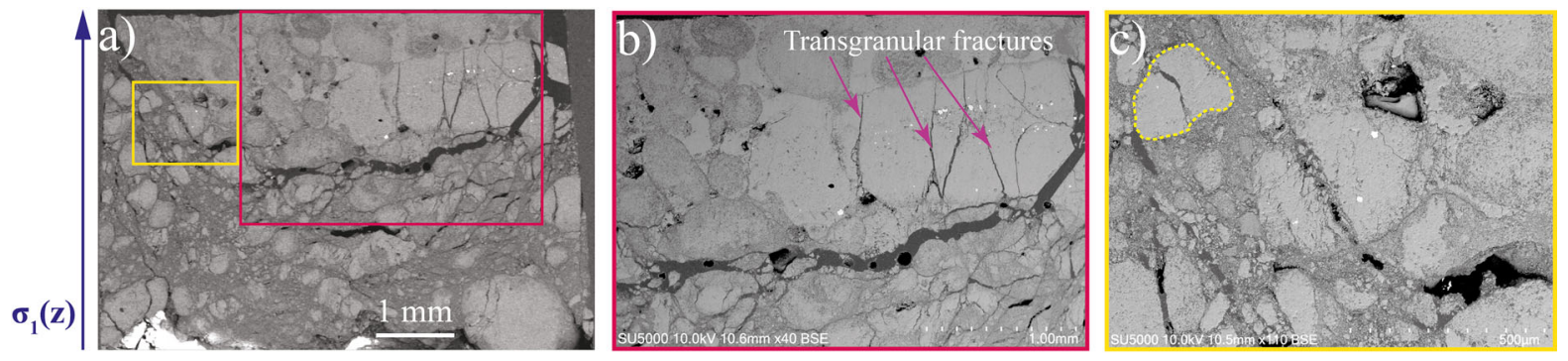

Figure 10

Scanning electron micrograph of sample Anstrude limestone 4 after failure. b Close up of area in (a). c Close up of area in (b). Some grains appear crushed and others host transgranular fractures parallel to $\sigma_{1}$

by significant amount of grain crushing leading to intense fragmentation of the rock. When samples were unloaded from the triaxial rig, regions of powdered rock formed cavities, which were filled by epoxy during the impregnation step. This effect led to an incomplete recovery of some samples (Fig. S10). However, all these samples show shear zones display with complex features that are reminiscent of various microscale mechanisms. Dilatational microfractures originated from macropores and propagated either along grain boundaries as intergranular microfractures or coalesced with transgranular fractures within ooids and grains. A shear zone in sample Anstrude \#2 (Fig. S9) contains microfractures that are oriented at $>30^{\circ}$ to $\sigma_{1}$. Also, the sample contains multiple fracture strands within a shear band that propagated across the sample length, spanning the entire rock volume. In the sample Anstrude \#5 (Fig. S10), a fault oriented at $\sim 30^{\circ}$ to $\sigma_{1}$ separates the highly crushed shear zone and the intact rock matrix. Shear zones in all the limestones host some intact ooids with transgranular microfractures. Regions outside the shear zone are relatively intact (right section of Fig. S10a, top section of Fig. 10a) and host transgranular fractures (top section of Fig. 10a).

For the Anstrude limestone \#4 sample (Fig. 10), compaction is accommodated by grain size reduction and the formation of transgranular fractures (Fig. 10a, b). The overall porosity decreased while contraction increased in this experiment (Fig. 8c-e). The formation and opening of micro fractures may prompt locally high dilation. In samples Anstrude \#5 and \#6 (Fig. 8f, g), dilation dominates deformation at failure, consistent with the formation of transgranular microfractures. The 3D tomograms of Anstrude limestone \#6 sample also show evidence of transgranular fractures (Fig. 3f).

\section{Discussion}

Our results present a detailed analysis of strain localization observed in three kinds of porous rocks, Adamswiller sandstone (23\% porosity), Bentheim sandstone $(22.8 \%)$ and Anstrude limestone (20\%). These rocks are deformed in the brittle regime under in-situ conditions with dynamic synchrotron X-ray tomography imaging. For the first time, the 4D evolution of incremental strain components of dilation, contraction and shear is compared to the evolutions of the bulk porosity and microstructure. In the brittle regime, porous rocks subjected to compressive loading may fail by shear localization, compaction localization, or cataclastic flow, depending on the applied confining stress and other parameters (e.g. Paterson \& Wong, 2005). In the present study, we applied confining stress of 5-30 MPa (Table 2). We consider $5 \mathrm{MPa}$ as a low confinement, $20 \mathrm{MPa}$ as an intermediate confinement, and $30 \mathrm{MPa}$ as a high confinement in the following discussion.

Strain localization mechanisms are influenced by parameters such as porosity, grain size distribution, pore fluid and confining pressure (e.g., Baud et al., 
2000; Scott \& Nielsen, 1991; Wong et al., 1997). Our study involves a broad range of values for these parameters; (1) three rock types with different grain size distributions, (2) pore fluid pressure (one of the Anstrude limestone experiments), and (3) confining pressures in the range 5-30 MPa. In the following discussion, we link these parameters to the observed strain localization process.

\subsection{Mechanisms of Brittle Deformation in Adamswiller and Bentheim Sandstones}

\subsubsection{Strain Localization and Its Link to Bulk Porosity Variations}

When approaching failure, strain localization in sandstone at low confinement (Bentheim sandstone experiments) proceeds by the accumulation of dilative strain, which results in increasing pore volume. Conversely, at increased confinement (Adamswiller sandstone) the dominant mechanism near failure is compaction, which reduces the porosity.

The sandstones, deformed under dry conditions in the present study, failed after a period of strain hardening (Fig. 1). The same behavior was observed in discrete element models for porous rocks (Wang et al., 2008). The observed relation between strain localization and porosity variation is a step beyond the previous studies on Adamswiller sandstone (Wong et al., 1997; Zhu and Wong, 1997) and Bentheim sandstone (Vajdova et al., 2004). These studies have shown that the evolution of porosity and stress state are coupled; porosity controls strain localization and subsequently the failure mode. With the present study, we can separate the total accumulated strain into dilative, contractive, and shear strain components (Figs. 7, 8): all of these components of the strain tensor are active with various amplitude. Deformation in Adamswiller sandstone is dominated by contractive strain (Figs. 7a, 8a) and reduction of porosity (Figs. 4b, 8a). Dilation increases near yield, at $75 \%$ of normalized macroscopic axial strain, becoming dominant over the contractive strain when failure approaches (Fig. 7a). This strain evolution is accompanied by a brief increase in mean porosity (Fig. 8a), consistent with the increase in local dilation. Porosity in Bentheim sandstone decreased during the initial phase of deformation, consistent with the observed dominance of contractive strain. From the yield point and until failure, dilation dominates (Figs. 7b, 8b), and porosity increases (Figs. 4b, 8b). Dominant strain component and associated porosity variations control the initiation of shear localization near macroscopic failure. Therefore, the variations in the volumetric strain components influence the strain localization process more than the deviatoric components in both sandstones in the present study.

Using the incremental strains calculated from digital volume correlation, we compare the localization of the highest local strain values of the Adamswiller and Bentheim sandstones to the Fontainebleau sandstone studied in Renard et al. (2019a). These Fontainebleau sandstones were deformed in the Hades rig, at confining pressures of 10-20 MPa, and we employed the same segmentation procedure and computational analysis as the present study. The Adamswiller and Bentheim sandstones have a higher porosity $(\sim 23 \%)$ than the Fontainebleau sandstone (5.5-7\% porosity). Differences in the internal microstructure of the sandstones, such as porosity, may produce variations in strain localization mechanisms. For example, discrete element method models of granular aggregates of varying porosity found that system-spanning, percolating force chains are more broadly distributed in lower porosity models than higher porosity models (McBeck et al., 2019a, 2019b). Differences in the spatial localization of the highest strains observed in Bentheim sandstone (Fig. 5, Movie V9) and Adamswiller sandstone (Movie V8), and Fontainebleau sandstone (Fig. 9 in Renard et al., 2019a) can be attributed to the differences in dominant strain localization behaviors, which may arise from the varying porosity. Both the Adamswiller and Bentheim sandstones experience a long compaction phase preceding the final shear localization. In contrast, Fontainebleau sandstone did not experience such an extended yielding phase (Renard et al., 2019a). The sandstones also differ in how the strains localized. For Fontainebleau sandstone sample F2 (Fig. 9b in Renard et al., 201), clustering trends in Von Mises strain clearly showed localization of a shear fault. For the Bentheim 
sandstone, the left-lateral shear strain (Fig. 5 and Movie V2) indicates the localization of a shear fault.

We may also compare the trends in the mean values of the strain invariants in Adamswiller and Bentheim sandstones with Fontainebleau sandstone (Fig. 11 in Renard et al., 2019a). Deformation and strain localization in Fontainebleau sandstone is dominated by dilative volumetric strain. Whereas in Adamswiller and Bentheim sandstones, von Mises strain shows high values indicating the strain localization has strong contributions from shear. For Bentheim sandstone, increasing trends in mean values (Fig. S7) as well as their cumulative values (Fig. S8) of dilation and Von Mises strains coincide with the increasing porosity beyond yield point. Therefore, both the local dilation and shear contribute to the changes in porosity. Considering the cumulative means of contractive volumetric strain and von Mises strain in Adamswiller sandstone, it is evident that the decreasing mean porosity is associated with the dominant deformation mechanisms of contraction and shear.

\subsubsection{Micromechanisms of Strain Localization}

In our sandstones with porosity of $\sim 23 \%$, the SEM images show the development of compacted zones characterized by grain crushing and transgranular fractures. The digital volume correlation data indicate that this development produced local dilation (Fig. 9). Microscale mechanisms of grain crushing and pore space dilation produce local dilatation and an increase in porosity, when subjected to low confinement (Bentheim sandstone). The contraction enabled by pore collapse does not overcome the increase of the local dilation, explaining the evolution of increasing macroscopic dilative strain. At intermediate confinement (Adamswiller sandstone), pore collapse with extensive grain crushing decreases the porosity, increasing the contraction.

The differences in porosity may produce differences in strain accumulation. Sandstones of lower porosities (5.5-7\%; Renard et al., 2019a) have higher amounts of cementation between the grains. This cementation causes the nucleation of damage to involve several microscale mechanisms: (i) poreemanated mode I cracks (Sammis \& Ashby, 1986) initiated along grain boundaries, (ii) following the development of intergranular fractures, transgranular fracturing occur at higher differential stresses, as explained by the Hertzian fracture concept (Johnson, 1982); (iii) then strain localization occurs by the coalescence of these microfractures either at failure (samples F1 and F3 in Renard et al., 2019a, 2019b) or at yield (sample F2 in Renard et al., 2019a, 2019b) and that grow to system-spanning faults. In contrast, in Adamswiller and Bentheim sandstones with higher porosities $(\sim 23 \%)$, failure is dominated by either pore space dilation, or pore collapse and grain crushing (resulting in the reduction of grain size) via the propagation of transgranular fractures (Fig. 9). In Bentheim sandstone, the acceleration of dilative strain near yield is attributed to initiation of transgranular fractures, resulting in grain crushing and sliding along the shear fault. At failure, the microstructure evolved into a localized shear zone with grain comminution. The post-failure tomograms show significant macroscopic contraction along the axial direction and dilation along the radial direction (e.g., Fig. 2a). In Adamswiller sandstone, the increase in the dilative strain near the yield suggests fracture opening, and perhaps grain crushing via transgranular fracture development. Transgranular fractures are signatures of grain crushing and observed in the post-failure microstructure of Adamswiller sandstone (Fig. 9). This grain crushing and collapse of the pore space resulted in the localization of a compaction shear band at failure.

\subsection{Mechanisms of Brittle Deformation in Anstrude Limestone}

\subsubsection{Strain Localization and Its Link to Porosity Variations}

Localization of strain in Anstrude limestone (20\% actual porosity) occurs through an interplay of compaction, dilation and shear, as observed in the 3D strain distributions (Movies V3-V7, Figs. 6, 7, S7, S8). This observation is in contrast to the sandstones (Movies V1 and V2, Figs. 5, 7), where either dilation or compaction is dominant. Independent of the dominant strain localization mechanisms, in each of the five experiments, porosity reduction 
(Fig. 4b) resulted in an overall macroscopic sample contraction (see tomograms at failure in Fig. 3). However, the applied confinement influences the porosity. Under low confinement (5 MPa), the porosity calculated from the microtomography data shows a nearly linear decreasing trend until failure. Whereas under relatively higher confinement (20-30 MPa), porosity decreased rapidly after the yield stress (Fig. 4b), associated with strain localization post yield.

A complex pore network defines the microstructure of many limestones, including a bimodal distribution of pores ( $\mathrm{Ji}$ et al., 2015; Lion et al., 2004). Strain localization in the Anstrude limestone studied here occurs through a combination of volumetric and shear strain increments: the highest magnitudes of these incremental strains generally overlap each other in these experiments (Figs. 5, 6; Movies V3-V7, Movies V10-V14). Our results agree with strain analyses on limestone that includes both macropores and micropores, including Indiana limestone with a porosity of $16 \%$ (Baud et al., 2021), Saint-Maximin limestone with a porosity of $37.9 \%$ (Abdallah et al., 2021), and Majella limestone with a porosity of 30-32\% (Ji et al., 2015). Our experiments indicate that strain localization results from an interplay of volumetric deformation and shear, with a strong compaction component. In previous studies (Abdallah et al., 2021; Baud et al., 2021; Ji et al., 2015) as well as for the Anstrude limestone in the present study, at the onset of strain localization, digital volume correlation data show the formation of compacting shear bands oriented at an angle oblique to $\sigma_{1}$. The angle of these deformation bands increase with applied confinement. The volumetric strain was primarily compactive (Abdallah et al., 2021, Baud et al., 2021; Ji et al., 2015), consistent with a continuous reduction in porosity in our experiments. In the Anstrude limestone, at a higher confinement (Anstrude samples \#2, \#4 and \#6, $\sigma_{2}-p_{0}=20 \mathrm{MPa}$ ) compacting shear bands have a higher angle than those deformed at lower confinement (Anstrude samples \#3 and \#5, $\sigma_{2}-p_{0}=5 \mathrm{MPa}$ ), where localization is dominated by dilation. Volumetric strain maps for Saint-Maximin limestone with 37.9\% porosity (Fig. 18 in Abdallah et al., 2021) show complex kinematic behavior including alternating dilation and compaction within the deformation bands. This observation is similar to the spatial clustering observed in our digital volume correlation data for Anstrude limestone (Fig. 6, Movies V3-V7, V10-14). Therefore, as strain localization is strongly influenced by volumetric compaction and shear strain, results obtained for Anstrude limestone are similar to that observed in other high porosity limestones. In this study, we link this strong influence of volumetric compaction to the continuous nonlinear decrease in porosity.

\subsubsection{Micromechanisms of Strain Localization}

Many carbonate rocks are characterized by bimodal porosity distributions, including microporosity and macroporosity. SEM images of post-failure microstructure for Anstrude limestone show evidence for such bimodal porosity (Figs. 10, S9, S10). The visible pore space with large voids within the deformed rock matrix that can be segmented in the $\mathrm{X}$-ray tomograms is the macroporosity. The microporosity occurs in (1) ooids/grains (speckle pattern in Fig. S9-c), (2) cemented regions in Fig. 10b, 10c) and in the periphery of macropores (fractures in Fig. S10). These observation are supported by the microstructural study of Anstrude limestone in Lion et al. (2004).

The complexity of the pore geometry and confining stress controls strain localization in Anstrude limestone, which are dependent on the confining pressure. The experiment Anstrude \#5, with a confining pressure of $5 \mathrm{MPa}$ (Fig. S10), hosted grain crushing, pore collapse and intense grain comminution within the shear band. In contrast, experiments Anstrude \#2 and \#4, with $20 \mathrm{MPa}$ confining stress (Figs. S9 and 10) hosted some dilatant fracture networks within the macroscopic shear band, in addition to these previous microstructures. Shear bands near failure are characterized by compacted rock, which is a result of pore collapse and the aforementioned microscale mechanisms. Hosting dilatant fracture networks at higher confinement may indicate the signatures of pore-emanating fractures that grow when failure is approached. Therefore, the microscale mechanisms that operate in Anstrude limestone are (1) pore collapse, (2) grain 
crushing with cataclasis and (3) pore-emanating fractures.

During mechanical compaction, anisotropy in the spatial distribution of damage around the macropores (Vajdova et al., 2004) results in pore collapse (Zhu et al., 2010). Macropore collapse produces an asymmetrical fracture network and distributed damage within the shear zone. In our experiments, inelastic compaction of the pore space resulted in the nucleation of dilatant fractures that localized (1) at the interface of a macropore and grain (intra-granular fractures), as shown in the post-failure SEM microstructures in Fig. S10) and (2) within the micropores (inter-granular fractures). Fractures originating from macropores can propagate along the gain boundaries as intergranular fractures, or within grains as intragranular fractures. This process results in grain breakage. Due to the development of fractures, those originating from micropores also result in grain breakage and pulverization of the rock. Therefore, coalescence and propagation of dilatant fractures originating from macro- and micropores result in the microstructural mechanism of grain crushing.

\section{Conclusion}

We present a comparative study of inelastic brittle deformation and strain localization in Adamswiller sandstone (23\% porosity), Bentheim sandstone (22.8\% porosity) and Anstrude limestone (20\% porosity), three kinds of reservoir rocks of comparable porosities at conditions of low to intermediate confining stresses (5-30 MPa). We show that the 4D evolution of the incremental local strain components of dilation, contraction and shear, are closely linked to variations in the bulk porosity and microstructure. Although all of the rock types experience strain localization via shear bands development, the deformation behavior differs depending on the microstructure of the rock, complexity of the pore geometry, and applied confinement. The sandstones are characterized by narrow grain size distributions and homogeneous pore geometry. When subjected to low confinement (Bentheim sandstone experiment), deformation is initially dominated by a porosity reduction at low differential stress, and beyond the yield stress deformation becomes dominated by dilative strain and higher porosity. Grain crushing and pore space dilation produces this local dilation and higher porosity. At intermediate confinement (Adamswiller sandstone), deformation proceeds by the accumulation of contractive strain and decreasing porosity. Pore collapse with extensive grain crushing produces local compaction and decreases the porosity. Anstrude limestone has a complex microstructure with ooids, producing a bimodal porosity distribution. Due to this bimodal porosity, strain localization mechanisms produce relative dispersion in the X-ray intensity, and thus deformation bands are difficult to distinguish from tomograms in these samples because their amplitude is small, and below the spatial resolution of the images. Hence, we used digital volume correlation to identify the strain localization that is not detectable directly from the tomograms. Under low confinement (Anstrude sample \#5 and \#3 near failure), accumulated dilative strain dominates during triaxial deformation and porosity decreases with loading. Increasing dilative strain is attributed to development of dilatant fractures within the compactive shear bands. At intermediate confinement (Anstrude samples \#2, \#4), compaction dominates and porosity decreases with loading. The presence of pore fluid in one experiment may facilitate the dominance of dilation (Anstrude sample \#6). The microstructural deformation mechanisms in Anstrude limestones include (i) pore collapse, (ii) pore-emanated fracturing that initiates at the periphery of the macropores and propagate as transgranular fractures within the shear zones, and (iii) cataclasis. Under low confinement, shear zones are defined by cataclasis and pervasive damage, whereas at intermediate confinement, they are characterized by dilatant fractures that extend across the sample. The experiment with pore fluid and intermediate confinement (sample Anstrude \#6), shows localization of conjugate shear bands. The Bentheim and Adamswiller sandstones, and the Anstrude limestone samples under low confinement are characterized by shorter yielding phases (in terms of axial strain) and the localization of strain is observed at the onset of failure, near the peak stress. Conversely, Anstrude limestones at intermediate confinement are characterized by long yielding 
phases, and the localization of the high local strains following yield and before macroscopic failure. Our results demonstrate that dynamic X-ray tomography experiments coupled with digital volume correlation analysis and SEM observations provide quantitative information about the deformation mechanisms of porous reservoir rocks, including linking strain at the microscale to the macroscopic deformation behavior of the samples.

In the present study we have used mathematical derivatives (divergence and curl) of incremental displacement fields to resolve strain into its components, namely dilative, contractive, right- and left-lateral shear. Rotational component (curl) was observed to be a better parameter for quantifying deformation (process) zones than a classical shear strain. Divergence is equal to the volumetric strain component. Curl represents magnitude of rotation as well as directional sense (right- and left-lateral) and provides additional information over classical computation of volumetric $\left(\mathrm{I}_{1}\right)$ and shear strains $\left(\left(3 \mathrm{~J}_{2}\right)^{1 / 2}\right)$. Using our experimental setup, more studies on different rock types are required to develop a generic and unified approach for computation of strain components for the rock volume. Further, cylindrical coordinate systems may help reveal the varying directional sense of the shear strain (right- and left-lateral) within the deformation zones of the rock. This technique could be employed in future studies.

\section{Acknowledgements}

The deformation apparatus was built by Sanchez Technologies. Elodie Boller, Paul Tafforeau, and Alexander Rack at beamline ID19 at ESRF provided advices on the design of the tomography setup. We thank the Editor Dr. Christian David and the reviewers, Dr. Teng-Fong Wong and Dr. Laurent Louis, for suggestions that improved the manuscript.

\section{Funding}

Open access funding provided by University of Oslo (incl Oslo University Hospital). This study received funding from the Norwegian Research Council (project HADES, Grant 250661). Beamtime was allocated at the European Synchrotron Radiation Facility (Long Term Proposal ES-295).

\section{Data Availability}

Data storage was provided by UNINETT Sigma2the National Infrastructure for High Performance Computing and Data Storage in Norway (project NS9073K). The X-ray tomography data (series of 3D volumes, 16 bytes gray scale) supporting the conclusions are available publicly at https://doi.org/10. $11582 / 2020.00058$.

\section{Declarations}

Conflict of interest The authors declare no conflict of interest.

Ethical approval This research does not raise ethical issues.

Open Access This article is licensed under a Creative Commons Attribution 4.0 International License, which permits use, sharing, adaptation, distribution and reproduction in any medium or format, as long as you give appropriate credit to the original author(s) and the source, provide a link to the Creative Commons licence, and indicate if changes were made. The images or other third party material in this article are included in the article's Creative Commons licence, unless indicated otherwise in a credit line to the material. If material is not included in the article's Creative Commons licence and your intended use is not permitted by statutory regulation or exceeds the permitted use, you will need to obtain permission directly from the copyright holder. To view a copy of this licence, visit http://creativecommons.org/licenses/by/4.0/.

Publisher's Note Springer Nature remains neutral with regard to jurisdictional claims in published maps and institutional affiliations.

\section{REFERENCES}

Abdallah, Y., Sulem, J., Bornert, M., Ghabezloo, S., \& Stefanou, I. (2021). Compaction banding in high-porosity carbonate rocks: 1 . Experimental observations. Journal of Geophysical Research: Solid Earth, 126(1), e2020JB020538.

Aydin, A. (1978) Small faults formed as deformation bands in sandstone. In J. D. Byerlee, \& M. Wyss (Eds.), Rock friction and earthquake prediction. Contributions to current research in geophysics (CCRG), Birkhäuser, Basel (Vol. 6). https://doi.org/ 10.1007/978-3-0348-7182-2_22 
Aydin, A., \& Johnson, A. M. (1978). Development of faults as zones of deformation bands and as slip surfaces in sandstone. Pure and Applied Geophysics, 116(4-5), 931-942.

Ballas, G., Soliva, R., Sizun, J. P., Fossen, H., Benedicto, A., \& Skurtveit, E. (2013). Shear-enhanced compaction bands formed at shallow burial conditions; Implications for fluid flow (Provence, France). Journal of Structural Geology, 47, 3-15.

Baud, P., Hall, S., Ji, Y., Wong, T. F., \& Heap, M. J. (2017c). The Brittle-Ductile transition in porous limestone imaged by X-ray computed tomography and digital image correlation. In Poromechanics VI, proceedings of the sixth biot conference on poromechanics (pp. 1782-1788).

Baud, P., Exner, U., Lommatzsch, M., Reuschlé, T., \& Wong, T. F. (2017a). Mechanical behavior, failure mode, and transport properties in a porous carbonate. Journal of Geophysical Research: Solid Earth, 122(9), 7363-7387.

Baud, P., Hall, S., Heap, M. J., Ji, Y., \& Wong, T. F. (2021). The Brittle-Ductile transition in porous limestone: Failure mode, constitutive modeling of inelastic deformation and strain localization. Journal of Geophysical Research: Solid Earth, 126(5), e2020JB021602.

Baud, P., Klein, E., \& Wong, T. F. (2004). Compaction localization in porous sandstones: Spatial evolution of damage and acoustic emission activity. Journal of Structural Geology, 26(4), 603-624.

Baud, P., Schubnel, A., Heap, M., \& Rolland, A. (2017b). Inelastic compaction in high-porosity limestone monitored using acoustic emissions. Journal of Geophysical Research: Solid Earth, 122(12), 9989-10008. https://doi.org/10.1002/2017JB014627

Baud, P., Schubnel, A., \& Wong, T. F. (2000). Dilatancy, compaction, and failure mode in Solnhofen limestone. Journal of Geophysical Research: Solid Earth, 105(B8), 19289-19303.

Bennett, R. A., Wernicke, B. P., Niemi, N. A., Friedrich, A. M., \& Davis, J. L. (2003). Contemporary strain rates in the northern Basin and Range province from GPS data. Tectonics, 22, 1008. https://doi.org/10.1029/2001TC001355,2

Bjørlykke, K. (1993). Fluid flow in sedimentary basins. Sedimentary Geology, 86(1-2), 137-158.

Bos, A. G., Spakman, W., \& Nyst, M. C. J. (2003). Surface deformation and tectonic setting of Taiwan inferred from a GPS velocity field. Journal of Geophysical Research, 108, 2458. https://doi.org/10.1029/2002JB002336,B10

Brace, W. F. (1978). Volume changes during fracture and frictional sliding: A review. Pure and Applied Geophysics, 116(4-5), 603-614.

Brantut, N., Heap, M. J., Baud, P., \& Meredith, P. G. (2014). Mechanisms of time-dependent deformation in porous limestone. Journal of Geophysical Research: Solid Earth, 119(7), 5444-5463.

Buades, A., Coll, B., \& Morel, J. M. (2005, June). A non-local algorithm for image denoising. In Computer society conference on computer vision and pattern recognition, 2005, IEEE (Vol. 2, pp. 60-65).

Cilona, A., Baud, P., Tondi, E., Agosta, F., Vinciguerra, S., Rustichelli, A., \& Spiers, C. J. (2012). Deformation bands in porous carbonate grainstones: Field and laboratory observations. Journal of Structural Geology, 45, 137-157.

Cilona, A., Faulkner, D. R., Tondi, E., Agosta, F., Mancini, L., Rustichelli, A., Baud, P., \& Vinciguerra, S. (2014). The effects of rock heterogeneity on compaction localization in porous carbonates. Journal of Structural Geology, 67, 75-93.
Croizé, D., Renard, F., \& Gratier, J. P. (2013). Compaction and porosity reduction in carbonates: A review of observations, theory, and experiments. In Advances in geophysics (Vol. 54, pp. 181-238). Elsevier.

Dansereau, V., Démery, V., Berthier, E., Weiss, J., \& Ponson, L. (2019). Collective damage growth controls fault orientation in quasibrittle compressive failure. Physical Review Letters, 122(8), 085501 .

Fortin, J., Stanchits, S., Dresen, G., \& Gueguen, Y. (2009). Acoustic emissions monitoring during inelastic deformation of porous sandstone: Comparison of three modes of deformation. Pure and Applied Geophysics, 166(5-7), 823-841.

Fossen, H., Schultz, R. A., Shipton, Z. K., \& Mair, K. (2007). Deformation bands in sandstone: A review. Journal of the Geological Society, 164(4), 755-769.

Fossen, H., Schultz, R. A., \& Torabi, A. (2011). Conditions and implications for compaction band formation in the Navajo Sandstone, Utah. Journal of Structural Geology, 33(10), 1477-1490.

Fossen, H., Soliva, R., Ballas, G., Trzaskos, B., Cavalcante, C., \& Schultz, R. A. (2018). A review of deformation bands in reservoir sandstones: Geometries, mechanisms and distribution. Geological Society, London, Special Publications, 459(1), 9-33.

Heap, M. J., Kushnir, A. R., Gilg, H. A., Wadsworth, F. B., Reuschlé, T., \& Baud, P. (2017). Microstructural and petrophysical properties of the Permo-Triassic sandstones (Buntsandstein) from the Soultz-sous-Forêts geothermal site (France). Geothermal Energy, 5(1), 26. https://doi.org/10.1186/ s40517-017-0085-9

Huang, L., Baud, P., Cordonnier, B., Renard, F., Liu, L., \& Wong, T. F. (2019). Synchrotron X-ray imaging in 4D: Multiscale failure and compaction localization in triaxially compressed porous limestone. Earth and Planetary Science Letters, 528, 115831.

Ji, Y., Hall, S. A., Baud, P., \& Wong, T. F. (2015). Characterization of pore structure and strain localization in Majella limestone by $\mathrm{X}$-ray computed tomography and digital image correlation. Geophysical Journal International, 200(2), 701-719.

Johnson, K. L. (1982). One hundred years of Hertz contact. Proceedings of the Institution of Mechanical Engineers, 196(1), 363-378.

Kandula, N., Cordonnier, B., Boller, E., Weiss, J., Dysthe, D. K., \& Renard, F. (2019). Dynamics of microscale precursors during brittle compressive failure in Carrara marble. Journal of Geophysical Research: Solid Earth, 124(6), 6121-6139.

Klein, E., Baud, P., Reuschlé, T., \& Wong, T. F. (2001). Mechanical behaviour and failure mode of Bentheim sandstone under triaxial compression. Physics and Chemistry of the Earth, Part a: Solid Earth and Geodesy, 26(1-2), 21-25.

Lion, M., Skoczylas, F., \& Ledésert, B. (2004). Determination of the main hydraulic and poro-elastic properties of a limestone from Bourgogne, France. International Journal of Rock Mechanics and Mining Sciences, 41(6), 915-925.

Lockner, D. A., Byerlee, J. D., Kuksenko, V., Ponomarev, A., \& Sidorin, A. (1992). Observations of quasistatic fault growth from acoustic emissions. In International geophysics (Vol. 51, pp. 3-31). Academic Press.

Lockner, D., Byerlee, J. D., Kuksenko, V., Ponomarev, A., \& Sidorin, A. (1991). Quasi-static fault growth and shear fracture energy in granite. Nature, 350(6313), 39-42. 
Louis, L., Wong, T. F., \& Baud, P. (2007). Imaging strain localization by X-ray radiography and digital image correlation: Deformation bands in Rothbach sandstone. Journal of Structural Geology, 29(1), 129-140.

Ma, X., \& Haimson, B. C. (2016). Failure characteristics of two porous sandstones subjected to true triaxial stresses. Journal of Geophysical Research: Solid Earth, 121(9), 6477-6498.

McBeck, J., Ben-Zion, Y., \& Renard, F. (2020). The mixology of precursory strain partitioning approaching brittle failure in rocks. Geophysical Journal International, 221(3), 1856-1872.

McBeck, J. A., Cordonnier, B., Vinciguerra, S., \& Renard, F. (2019b). Volumetric and shear strain localization in Mount Etna basalt. Geophysical Research Letters, 46, 2425-2433.

McBeck, J., Kobchenko, M., Hall, S. A., Tudisco, E., Cordonnier, B., Meakin, P., \& Renard, F. (2018). Investigating the onset of strain localization within anisotropic shale using digital volume correlation of time-resolved X-ray microtomography images. Journal of Geophysical Research: Solid Earth, 123(9), 7509-7528.

McBeck, J., Mair, K., \& Renard, F. (2019a). How porosity controls macroscopic failure via propagating fractures and percolating force chains in porous granular rocks. Journal of Geophysical Research: Solid Earth, 124(9), 9920-9939.

Menéndez, B., Zhu, W., \& Wong, T. F. (1996). Micromechanics of brittle faulting and cataclastic flow in Berea sandstone. Journal of Structural Geology, 18(1), 1-16.

Mirone, A., Brun, E., Gouillart, E., Tafforeau, P., \& Kieffer, J. (2014). The PyHST2 hybrid distributed code for high speed tomographic reconstruction with iterative reconstruction and a priori knowledge capabilities. Nuclear Instruments and Methods in Physics Research Section B: Beam Interactions with Materials and Atoms, 324, 41-48.

Mittone, A., Manakov, I., Broche, L., Jarnias, C., Coan, P., \& Bravin, A. (2017). Characterization of a sCMOS-based highresolution imaging system. Journal of Synchrotron Radiation, 24(6), 1226-1236.

Nagel, N. B. (2001). Compaction and subsidence issues within the petroleum industry: From Wilmington to Ekofisk and beyond. Physics and Chemistry of the Earth, Part a: Solid Earth and Geodesy, 26(1-2), 3-14.

Olsson, W. A., \& Holcomb, D. J. (2000). Compaction localization in porous rock. Geophysical Research Letters, 27(21), 3537-3540.

Olsson, W. A., Holcomb, D. J., \& Rudnicki, J. W. (2002). Compaction localization in porous sandstone: Implications for reservoir mechanics. Oil \& Gas Science and Technology, 57(5), 591-599.

Paganin, D., Gureyev, T. E., Pavlov, K. M., Lewis, R. A., \& Kitchen, M. (2004). Phase retrieval using coherent imaging systems with linear transfer functions. Optics Communications, 234(1-6), 87-105.

Paterson, M. S., \& Wong, T. F. (2005). Experimental rock deformation-the brittle field. Springer Science \& Business Media.

Pittman, E. D. (1971). Microporosity in carbonate rocks. $A A P G$ Bulletin, 55(10), 1873-1878.

Rath, A., Exner, U., Tschegg, C., Grasemann, B., Laner, R., \& Draganits, E. (2011). Diagenetic control of deformation mechanisms in deformation bands in a carbonate grainstone. $A A P G$ Bulletin, 95(8), 1369-1381.

Renard, F., Cordonnier, B., Dysthe, D. K., Boller, E., Tafforeau, P., \& Rack, A. (2016). A deformation rig for synchrotron microtomography studies of geomaterials under conditions down to $10 \mathrm{~km}$ depth in the Earth. Journal of Synchrotron Radiation, 23, 1030-1034.

Renard, F., Cordonnier, B., Kobchenko, M., Kandula, N., Weiss, J., \& Zhu, W. (2017). Microscale characterization of rupture nucleation unravels precursors to faulting in rocks. Earth and Planetary Science Letters, 476, 69-78.

Renard, F., McBeck, J., Cordonnier, B., Zheng, X., Kandula, N., Sanchez, J. R., Kobchenko, M., Noiriel, C., Zhu, W., Meakin, P., Fusseis, F., \& Dysthe, D. K. (2019a). Dynamic in situ threedimensional imaging and digital volume correlation analysis quantify strain localization and fracture coalescence in sandstone. Pure and Applied Geophysics, 176, 1083-1115. https:// doi.org/10.1007/s00024-018-2003-X

Renard, F., McBeck, J., Kandula, N., Cordonnier, B., Meakin, P., \& Ben-Zion, Y. (2019b). Volumetric and shear processes in crystalline rock approaching faulting. Proceedings of the National Academy of Sciences, 116, 16234-16239. https://doi.org/10. 1073/pnas.1902994116

Renard, F., Weiss, J., Mathiesen, J., Ben-Zion, Y., Kandula, N., \& Cordonnier, B. (2018). Critical evolution of damage toward system-size failure in crystalline rock. Journal of Geophysical Research: Solid Earth, 123(2), 1969-1986.

Renshaw, C. E., \& Schulson, E. M. (2001). Universal behaviour in compressive failure of brittle materials. Nature, 412(6850), 897-900.

Rimmelé, G., Barlet-Gouédard, V., \& Renard, F. (2010). Evolution of the petrophysical and mineralogical properties of two reservoir rocks under thermodynamic conditions relevant for $\mathrm{CO}_{2}$ geological storage at $3 \mathrm{~km}$ depth. Oil \& Gas Science and Technology-Revue De L'institut Français Du Pétrole, 65(4), 565-580.

Rotevatn, A., Thorsheim, E., Bastesen, E., Fossmark, H. S., Torabi, A., \& Sælen, G. (2016). Sequential growth of deformation bands in carbonate grainstones in the hangingwall of an active growth fault: Implications for deformation mechanisms in different tectonic regimes. Journal of Structural Geology, 90, 27-47.

Rustichelli, A., Tondi, E., Agosta, F., Cilona, A., \& Giorgioni, M. (2012). Development and distribution of bed-parallel compaction bands and pressure solution seams in carbonates (Bolognano Formation, Majella Mountain, Italy). Journal of Structural Geology, 37, 181-199.

Rutter, E. H. (1983). Pressure solution in nature, theory and experiment. Journal of the Geological Society, 140(5), 725-740.

Sammis, C. G., \& Ashby, M. F. (1986). The failure of brittle porous solids under compressive stress states. Acta Metallurgica, 34(3), 511-526.

Schutjens, P. M. T. M., Hausenblas, M., Dijkshoorn, M., \& Van Munster, J. G. (1995). The influence of intergranular microcracks on the petrophysical properties of sandstone-Experiments to quantify effects of core damage. In Proc. int. symp. soc. core analysts (Vol. 9524, pp. 1-12).

Scott, T. E., \& Nielsen, K. C. (1991). The effects of porosity on the brittle-ductile transition in sandstones. Journal of Geophysical Research: Solid Earth, 96(B1), 405-414.

Shipton, Z. K., \& Cowie, P. A. (2001). Damage zone and slipsurface evolution over $\mu \mathrm{m}$ to $\mathrm{km}$ scales in high-porosity Navajo sandstone, Utah. Journal of Structural Geology, 23(12), 1825-1844.

Tondi, E., Rustichelli, A., Cilona, A., Balsamo, F., Storti, F., Napoli, G., Agosta, F., Renda, P., \& Giorgioni, M. (2016). 
Hydraulic properties of fault zones in porous carbonates, examples from central and southern Italy. Italian Journal of Geosciences, 135(1), 68-79.

Tudisco, E., Andò, E., Cailletaud, R., \& Hall, S. A. (2017). TomoWarp2: A local digital volume correlation code. SoftwareX, 6, 267-270.

Van Baaren, J. P., Vos, M. W., \& Heller, H. K. J. (1990). Selection of outcrop samples for acoustic measurements on reservoir rocks. Delft University of Technology.

Vajdova, V., Baud, P., \& Wong, T. F. (2004). Permeability evolution during localized deformation in Bentheim sandstone. Journal of Geophysical Research: Solid Earth, 109, B10406. https://doi.org/10.1029/2003JB002942

Vajdova, V., Zhu, W., Chen, T. M. N., \& Wong, T. F. (2010). Micromechanics of brittle faulting and cataclastic flow in Tavel limestone. Journal of Structural Geology, 32(8), 1158-1169.

Wang, B., Chen, Y., \& Wong, T. F. (2008). A discrete element model for the development of compaction localization in granular rock. Journal of Geophysical Research: Solid Earth, 113, B03202. https://doi.org/10.1029/2006JB004501
Wong, T. F., \& Baud, P. (2012). The brittle-ductile transition in porous rock: A review. Journal of Structural Geology, 44, 25-53.

Wong, T. F., David, C., \& Zhu, W. (1997). The transition from brittle faulting to cataclastic flow in porous sandstones: Mechanical deformation. Journal of Geophysical Research: Solid Earth, 102(B2), 3009-3025.

Zheng, X., Cordonnier, B., McBeck, J., Boller, E., Jamtveit, B., Zhu, W., \& Renard, F. (2019). Mixed-mode strain localization generated by hydration reaction at crustal conditions. Journal of Geophysical Research: Solid Earth, 124(5), 4507-4522.

Zhu, W., Baud, P., \& Wong, T. F. (2010). Micromechanics of cataclastic pore collapse in limestone. Journal of Geophysical Research: Solid Earth, 115, B04405. https://doi.org/10.1029/ 2009JB006610

Zhu, W., \& Wong, T. F. (1997). The transition from brittle faulting to cataclastic flow: Permeability evolution. Journal of Geophysical Research: Solid Earth, 102(B2), 3027-3041.

Zuluaga, L. F., Fossen, H., \& Rotevatn, A. (2014). Progressive evolution of deformation band populations during Laramide fault-propagation folding: Navajo Sandstone, San Rafael monocline, Utah, USA. Journal of Structural Geology, 68, 66-81.

(Received March 17, 2021, revised November 1, 2021, accepted November 5, 2021, Published online November 17, 2021) 